$A 11101310628$

\title{
NBSIR 82-2630
}

\section{Development and Evaluation of $A$ Test Method for Shower Heads}

U.S. DEPARTMENT OF COMMERCE

National Bureau of Standards

National Engineering Laboratory

Center for Building Technology

Washington, DC 20234

\section{December 1982}

Issued February 1983

Sponsored by:

Iffice of Policy Development and Research

S. Department of Housing and Urban Development 'ashington, DC 20410 



\section{DEVELOPMENT AND EVALUATION OF A} TEST METHOD FOR SHOWER HEADS

Paul Kopetka

Lawrence Galowin

U.S. DEPARTMENT OF COMMERCE

National Bureau of Standards

National Engineering Laboratory

Center for Building Technology

Washington, DC 20234

December 1982

Issued February 1983

Sponsored by:

Office of Policy Development and Research

U.S. Department of Housing and Urban Development

Washington, DC 20410

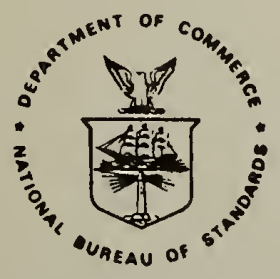

U.S. DEPARTMENT OF COMMERCE, Malcolm Baldrige, Secretary NATIONAL BUREAU OF STANDARDS, Ernest Ambler, Director 

A proposed test method for the evaluation of low-flow shower heads or flow-restrictor-modified shower heads was developed. The test method provides for the measurement of the principal operating characteristics, i.e., pressure-flow rate dependency and the shower spray distribution. The requirements for laboratory instrumentation suitable for application to the apparatus and the procedures for testing were established. A water collection device, "sector rig", was designed and constructed for the measurement of spray distribution patterns. Experiments were conducted with a small number of shower heads to determine the suitability of the proposed test method. The experimental results indicated the applicability of the method for measurement of spray distribution patterns and other conventional hydraulic performance parameters. A proposed test method for evaluation of shower heads was prepared based upon the analysis of the test results. The test method includes the specification of instrumentation, apparatus, procedures, measurements, and data reduction.

Key words: plumbing; shower heads; water conservation; water supply devices. 


\section{PREFACE}

This report is one of a group documenting National Bureau of Standards (NBS) research and analysis efforts in developing water conservation test methods, models for technical and economic analysis, and strategies for implementation and acceptance of practices. This work 18 sponsored by the Department of Housing and Urban Development, Office of Policy Development and Research, Energy, Building Technology and Standards Divisions, under Interagency Agreement $\mathrm{H}-48-78$. 


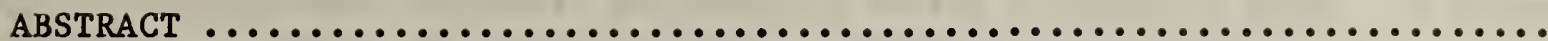

1. INTRODUCTION $\ldots \ldots \ldots \ldots \ldots \ldots \ldots \ldots \ldots \ldots \ldots \ldots \ldots \ldots \ldots \ldots \ldots \ldots \ldots \ldots \ldots \ldots \ldots \ldots \ldots \ldots$

2. EXPERIMENTAL APPROACH $\ldots \ldots \ldots \ldots \ldots \ldots \ldots \ldots \ldots \ldots \ldots \ldots \ldots \ldots \ldots \ldots \ldots \ldots \ldots \ldots \ldots \ldots . \ldots$

2.1 Laboratory Procedures $\ldots \ldots \ldots \ldots \ldots \ldots \ldots \ldots \ldots \ldots \ldots \ldots \ldots \ldots \ldots \ldots \ldots \ldots \ldots . \ldots$

2.2 Apparatus $\ldots \ldots \ldots \ldots \ldots \ldots \ldots \ldots \ldots \ldots \ldots \ldots \ldots \ldots \ldots \ldots \ldots \ldots \ldots \ldots \ldots \ldots \ldots$

2.2.1 Water Delivery System .......................... 6

2.2.2 Mixing and Conditioning System .................. 7

2.2.3 Shower Head Mounting/Clamping Device ............... 7

2.2.4 Shower Spray Collection Device - Sector Rig ........... 7

2.3 Instrumentation $\ldots \ldots \ldots \ldots \ldots \ldots \ldots \ldots \ldots \ldots \ldots \ldots \ldots \ldots \ldots \ldots \ldots \ldots$

2.4 Test Procedure $\ldots \ldots \ldots \ldots \ldots \ldots \ldots \ldots \ldots \ldots \ldots \ldots \ldots \ldots \ldots \ldots \ldots \ldots \ldots \ldots \ldots \ldots$

2.5 Data Reduction $\ldots \ldots \ldots \ldots \ldots \ldots \ldots \ldots \ldots \ldots \ldots \ldots \ldots \ldots \ldots \ldots \ldots \ldots \ldots \ldots \ldots$

3. TEST RESULTS $\ldots \ldots \ldots \ldots \ldots \ldots \ldots \ldots \ldots \ldots \ldots \ldots \ldots \ldots \ldots \ldots \ldots \ldots \ldots \ldots \ldots \ldots \ldots \ldots \ldots \ldots \ldots$

3.1 Water Distribution $\ldots \ldots \ldots \ldots \ldots \ldots \ldots \ldots \ldots \ldots \ldots \ldots \ldots \ldots \ldots \ldots \ldots \ldots \ldots$

3.1.1 Radial and Circumferential Water Distribution ......... 12

3.1.2 Measured and Metered Water ...................... 13

3.2 Shower Head Orientation $\ldots \ldots \ldots \ldots \ldots \ldots \ldots \ldots \ldots \ldots \ldots \ldots \ldots \ldots \ldots \ldots \ldots$

3.3 Water Flow Rate vs Pressure ............................ 14

4. RECOMMENDATIONS FOR IMPLEMENTATION OF SHOWER HEAD TEST METHOD ...... 15

4.1 Test Method Guides ............................... 15

4.1.1 Shower Heat Test Configuration .................. 15

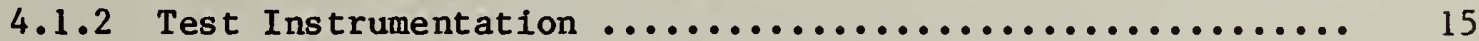

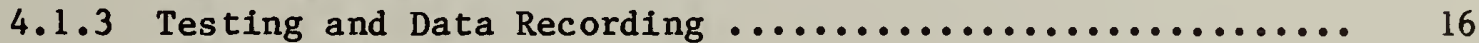

4.1 .4 Results ...................................... 18

5. CONCLUSIONS $\ldots \ldots \ldots \ldots \ldots \ldots \ldots \ldots \ldots \ldots \ldots \ldots \ldots \ldots \ldots \ldots \ldots \ldots \ldots \ldots \ldots \ldots \ldots \ldots$

6. REFERENCES .......................................... 21 
TABLES OF CONTENTS (Continued)

$\underline{\text { Page }}$

APPENDIX A. WATER COLLECTION DEVICE CALIBRATION PROCEDURE AND RESULTS .. 36

APPENDIX B. ALTERNATIVE METHODS OF WATER DEPTH MEASUREMENT .......... 38

APPENDIX C. WATER COLLECTION DISTRIBUTIONS .................... 41 


\section{LIST OF FIGURES}

$\underline{\text { Page }}$

Figure 1. Water collection device - "sector rig" - geometry and dimensions

Figure 2. Shower head test configuration

Figure 3. Distribution of water collected in sector rig compartments .. 30

Figure 4. Distribution of water collected in sector rig compartments .. 31

Figure 5A. Measured vs metered water - warm water .............. 32

Figure 5B. Measured vs metered water - hot water ................ 32

Figure 6 A. Water flow rate vs pressure $\ldots \ldots \ldots \ldots \ldots \ldots \ldots \ldots \ldots \ldots \ldots \ldots \ldots \ldots$

Figure 6B. Water flow rate vs pressure ......................... 34

Figure 7. Water flow rate vs pressure - flow restrictors ........... 35

Figure B-1. Alternative test configuration - manometer bank .......... 39

Figure B-2. Alternative test configuration - pressure transducer bank ... 40 


\section{LIST OF TABLES}

Page

Table 1. List of Laboratory Instrumentation ................... 22

Table 2. Shower Head/Flow Restrictor Classificiations ............ 23

Table 3. Water Distributions in Sector Compartments at 138 kPa ...... 24

Table 4. Water Distributions in Sector Compartments at $344 \mathrm{kPa} \ldots \ldots . .25$

Table 5. Water Distributions in Sector Compartments at $551 \mathrm{kPa} \ldots \ldots . .26$

Table 6. Shower Head Orientation Test Results ................... 27

Table A-1. Water Collection Device Calibration Results ............. 37 
Requirements for residential water conservation have resulted from a number of factors, such as limited water resources, shortages during drought conditions, inadequate processing capacity for supply of potable water and treatment of wastewater, growth of population in arid areas, and announced national policy [1].* Potable water consumption in residential usage is distributed as follows: approximately 40 percent of the total for flushing of water closets; bathing consumes about 30 percent, and all other uses comprise the remaining 30 percent $[2,3,4]$. Reduction in hot water usage with low-flow devices results in energy conservation as indicated in the California drought experience $[4,5]$. The U.S. Department of Energy (DoE) Low-Cost/No-Cost Program included inserting flow restrictors in showers for energy reduction. Cost benefits due to energy conservation are usually greater than those directly attributable to water conservation [5].

Grey water systems (water reuse to reduce potable water consumption) are frequently considered as alternatives for providing water for flushing of water closets [6] and sometimes partially treated for landscape applications. The primary single source of grey water is from bathing. If significant reduction in the use of potable water is achieved through reuse/recycle for water closet usage, then bathing water becomes a more significant parameter in potable water consumption and could represent up to 50 percent of total residential usage. Similarly, if very low-flow water closets (using potable water) gain broader acceptance, the percentage of residential potable water usage for bathing increases significantly.

Reduced flow shower heads or flow restrictor modified shower heads have proved to be effective in reducing water consumption $[2,3,4,5]$. The basis for selection of a new low-flow or retrofit shower device which provide adequate and satisfactory performance levels for flow rate pressure dependency or patterns of water distribution is not well established. There is generally little consumer oriented label information provided to describe the performance of new shower heads, e.g., the flow rates, desired range of supply pressures or the water spray distribution (cone angle). The need for a method to provide essential performance requirements and rating methods for various plumbing devices was recognized in the "Water Efficiency Labeling Act" introduced in Congress [7]; although the legislation was not passed, it is indicative of the concerns for performance requirements through the establishment of test methods for evaluation and rating information.

Classification of shower bathing activities and equipment was identified in "Space Requirements for Showers" [8]. The specifications for shower stalls developed by the investigators related to the functions and space requirements for space accommodations in which to perform wetting, soaping, rinsing and drying of the entire body. The scope of that study was limited to oniy those four functional elements and did not attempt to establish any linkage between

* Numbers in brackets indicate references. 
the functions performed within the space to the characteristics of the source of water and its distribution, 1.e., shower head. The investigators established a second (hydraulic) classification group that identified the need for research on hydraulic performance for the shower spray, adjustment, water flow rate, and water temperature as important shower parameters which were beyond the scope of that $\mathbf{s}$ tudy.

The specific shower head performance requirements to provide hygienic sanitary functions, $1 . e$. , the removal of dirt, body oil, sweat, bacteria, and soap film/ suds, do not appear to be established in the literature. Also, under existing standards $[9,10]$, the impact of shower streams on the body, particularly upon extremely sensitive areas of the body, do not appear to be characterized or quantified. Measures of comfort parameters that tend to satisfy user needs, e.g., very hot showers for relaxation and "needle" showers for awakening or following an exercise period, are largely unknown. The disincentives resulting from user dissatisfaction with reduced flow devices in attaining water conservation program goals have been documented when poor performance occurs [11]. Lowflow shower heads or retrofit add-on restrictors are available for replacement by the user/consumer with ease and little skill requirements. Consequently, low-flow showers with nonacceptable performance (i.e., strong variation of flow rate with pressure, inadequate water distribution over the body, narrow high intensity streams, excessive amounts of water striking the shower stall wall or shower curtain, etc.) have great potential for discouraging water/energy savings practices.

Existing codes and standards, federal specifications, and criteria for requirements of low-flow shower heads $[9,10]$ emphasize materials and durability requirements. The performance requirements for hydraulic related parameters are usually limited to the flow rate dependency on pressure and broadly prescribed tolerances on the cone angle. The requirements for the test measurement methods, instrumentation, and formats for data recording and evaluation of results are inadequately described.

The objectives of the research on low-flow shower heads were: (a) development of a laboratory-based hydraulic performance test evaluation method; (b) establishment of recommendations for test evaluation guidelines and criteria with potential rating applications suitable for standards and codes; (c) limited validation of laboratory selection criteria in a pilot field demonstration based upon user acceptance tests. Selected aspects of acceptability of low-flow rate showers by users are to be determined in the HUD demonstration program and to establish whether changes in patterns of usage occur, particularly if the time period and temperature setting are altered with reduced flows.

The shower head is a device which converts the pressure available at the fixture into a spray (or fine streams) as a results of the pressure drop across an assembly of orifices. The design of the spray nozzle is usually axisymmetric and in simpler designs uniformly distributed discharge orifices are provided to develop an essentially conical spray. Selectively, attempts are made to vary the spray pattern through the geometrical distribution of the orifices and the flow rate controlled by the orifice size. In some designs, a variable control is provided for the user to manually change the spray distribution pattern and 
the flow rate. The current trend in low-flow showerhead designs is to reduce the cone angle in order to focus the spray onto the body thereby reducing the water which would have been directed to the shower enclosure. The requirement for removal of soap suds from shampooed hair can be achieved more satisfactorily by a narrower spray at low flow rates.

For water conservation the flow rate is of particular importance since the total water consumption is dependent on the time period in use; therefore, the flow rate is an indicator of the water conserving potential. Measurement methods for determination of flow rate are relatively simple, e.g., in-line flow meters or volumetric collection in calibrated tanks over given time periods. The specification of a limiting cone angle, prescribed in standards, only represents the extent of wetted surface area at a prescribed distance from the shower head. The measurement method for the hydraulic effectiveness of the conversion of water supply flow energy (or total head) into a distributed spray pattern, over a representative wetted area, has not been developed. With reduced water usage the distribution patterns provide a parameter that could of greater significance than the cone angle. Body surface wetting patterns and the shearing away of suds from the body may in the future be included by behavioral researchers as a parameter of the "quality of a shower" related to removal of dirt and body oils or bacteria.

A water spray collection device, subsequently referred to as the sector test rig, was developed as a measurement method to determine the shower distribution characteristics.

The development of the laboratory test procedures, equipment, instrumentation, and results obtained in the experiments with the sector test rig are discussed in the following sections of the report. The equipment installation and test requirements were based upon the premise that any conventional hydraulic test facility or plumbing manufacturer quality control laboratory, with existing equipment and instrumentation, should be able to readily duplicate the evaluation procedure if adopted through the voluntary consensus standards process. 


\subsection{LABORATORY PROCEDURES}

The laboratory test plan was developed to fulfill the following goals: (i) establish the basis for measurement methods(s) to provide quantifiable levels of performance for low-flow shower heads; (ii) conduct experiments to evaluate the suitability of the instrumenation and measurement technique(s); (iii) determine the applicability of the compartmented sector test rig to provide test results for evaluation of the performance parameters. The study of the utility of the test methods for evaluation of the shower spray distribution characteristic(s) was to establish the basis for a standard evaluation procedure. The methods would be applicable for federal guidelines and become a reference source to voluntary consensus standards organizations considering requirements for water conserving devices.

The measurement techniques and water spray collection device were required to provide data on the following shower head operating characteristics:

(a) Water flow rate as a function of supply line pressure,

(b) Radial and circumferential water distribution characteristics at a reference distance from the shower head,

(c) A volumetric distribution function to represent the flow quantity delivered over the wetted area at a reference distance from the shower head,

(d) Water temperature effects on variability of flow rate, spray distribution, and cone angle (or its improvement), and

(e) Variability of water flow rate, distribution and cone angle as a function of representative water supply pressures for adjustable and nonadjustable shower sprays and angular orientation (tilt) head positions.

Other shower spray characteristics, such as droplet size and water stream velocity, were not considered in the test procedures. The hydraulic flow parameters in (a), and elements of (d) and (e) were measurable with commercially available instrumentation; the water collection device - sector rig illustrated in figure 1 - was developed to provide the shower spray distribution characteristics of (b), (c), (d), and (e) with limited application to (a). In addition, a mounting/clamping device to maintain alignment of the shower head assembly was required for the shower head test apparatus. A schematic of this configuration is shown in figure 2 .

The customary basis for evaluating the performance of low-flow shower heads has been the determination of the water flow rate and cone angle as a function of the pressure measured at the shower head. The test pressure range should be representative of water supply systems across the country. In some communities, water is delivered to residential dwellings without pressure regulators, at 
pressures as high as $689 \mathrm{kPa}$ (100 psi); in other places, particularly in hilly terrain, line pressures may drop to as low as $68.9 \mathrm{kPa}$ (10 psi). The range from 68.9 to $689 \mathrm{kPa}$ (10 to $100 \mathrm{psi}$ ) was adopted for the test program.

The water flow rate can be obtained by: (1) a water flow meter in the supply line, or (2) summing the individual volumes of water collected in each sector compartment of the water collection device over the total time period. The use of a flow meter also provides a supplementary measurement useful in determining the overall accuracy of the data collection procedures, $i . e .$, the measurement of the total quantity of water collected during the time interval in the sector rig. Both flow measurement procedures were utilized in the laboratory testing and are included in the recommendations for the proposed shower head test method. The water pressure can be measured with either a dial pressure gauge or transducer located at a point close to the shower head; both measurements were used in the laboratory, but that redundancy in the measurement procedure is not required for the proposed shower head test method.

To obtain data on shower spray patterns, items (b), (c), (d), and (e), above, and establish a basis for a standardized test method, it was necessary to provide a simple means of measurement for the distributed volumes of water. The configuration for the test water collection apparatus was selected to be circular annular cylinders divided into sectors, since shower heads are generally designed to produce axisymmetrical spray distribution patterns; however, offsets in new shower head assemblies or retrofit flow restrictors may not maintain the original circular distribution patterns. Other grid arrays for collectors comprised of squares, triangles, or diamond shaped cross sectional areas were rejected because generally a large number of "cells" would be required or the simplicity of the test collection device could not be maintained. Division of the annular rings into $60^{\circ}$ (pie shaped) sectors provides for collection of the distributed spray in the circumferential as well as radial directions.

Measurements in the radial direction provides a means of estimating the spray cone angle; measurement of the circumferential shower spray distribution provides information about the uniformity within the circular bands. The capability of the water collection device to indicate the shower spray cone angle was desired since the cone angle has conventionally been a measure for shower head requirements [10]. Improvement in accuracy of determination of the geometric cone angle would require a greater number of radial collector rings than shown in figure 1 (smaller radial intervals are necessary). For greater accuracy in determining circumferential variations sector angles less than $60^{\circ}$ are required.

To account for the effects of water supply temperature on shower head performance (as indicated by previous studies [4]), all the shower heads were tested at two temperatures, $29.4^{\circ}$ and $40.6^{\circ} \mathrm{C}\left(85^{\circ}\right.$ and $\left.105^{\circ} \mathrm{F}\right)$ with a tolerance of $2.5^{\circ} \mathrm{C}\left( \pm 5^{\circ} \mathrm{F}\right)$. These two temperatures were selected as representative levels 
for "warm" and "hot" showers*. Flow rate regulation in many shower devices depends upon pressure sensitive deformable rings or perforated discs (formulated from elastomers) to regulate the flow rate. The flow rate changes will depend upon the specific type of shower head, the design of the rate control element, and the construction and composition of its components. The temperature affects the viscosity of the water as well as the dimensions of the flow restricting orifices through expansion or contraction of the material. The temperature change can alter the elastic deformation response of the pliable orifice materials (of volume rate controllers) to the applied water pressure. The effects of temperature changes may result in different flow rate-pressure relationships.

Previously conducted water-saving shower head tests [4] which incorporated an integral ball-joint flow restrictor indicated that a noticeable deviation of the flow rate-pressure relationship occurred when the shower head was tilted with respect to the mounting pipe. Consequently, provision was made for shower head tests with an arigle offset with respect to the mounting pipe, (tilted) as well as vertically aligned (plumb line), included in the study of the test method for the determination of the flow effects, $1 . e .$, both the flow ratepressure relationship and shower spray distribution characteristics. The maximum offset position is governed by the stop limits due to the physical construction of the shower head (see figure 2). The apparatus should permit duplication of any offset that could be experienced in actual installations.

Additional test method developments were required for shower heads with manually operated control mechanisms (integral to the shower head but adjustable externally) for variable shower spray since a large number of such shower heads are commercially available. Since the flow rate-pressure relationship and the shower spray characteristics may vary depending on the wide range of adjustments possible in the spray control mechanisms, the simplified test procedure was limited to: ( 1 ) the extreme settings physically allowable; these control positions generally represent the two operating extremes for the shower head ( $1 . e .$, minimum or maximum flow, fine or coarse spray, small or large cone angle, etc.); and (ii) additional settings, arbitrarily selected, between the two extreme limits.

\subsection{APPARATUS}

The installation of the apparatus, as shown in figure 2, consists of a controllable water delivery system, mixing and flow control system, shower head mounting/clamping device, and the water collection components.

\subsubsection{Water Delivery System}

Water for the shower head tests was supplied from a high pressure water system (from pneumatic boost storage tanks in the laboratory facility) to provide the test conditions up to $689 \mathrm{kPa}$ (100 psi) required for the test program. Hot water was delivered to the mixing system from a conventional 454 \& ( 120 gallon))

*Cold water temperatures in storage tanks may vary due to the source of supply and heated/air conditioned environments. 
residential water heater maintained at $82^{\circ} \mathrm{C}\left(180^{\circ} \mathrm{F}\right)$ located adjacent to the test area.

\subsubsection{Mixing and Conditioning System}

The water mixing and flow control system blended the cold and hot water to establish the test water temperature and regulate the quantity of flow to the shower head. The system consisted of a thermostatically controlled mixing valve, a throttling valve, water flow indicating meter, and measuring components. The water flow temperature was set and regulated by the mixing valve. The throttling valve, connected to the output of the mixing valve, was used to establish the water flow rate. A solenoid valve was used to quickly start and stop the water flow to the shower head.

\subsubsection{Shower Head Mounting/Clamping Device}

The shower head mounting/clamping device securely held the shower head in the desired vertical orientation (above the sector rig). The water supply pipe could be displaced to a "tilted" position; the configuration and the test positions for the mounting pipe are also shown in figure 2. The shower head was connected to the water supply pipe $0.6 \mathrm{~m}$ (24 in.) length, $1 / 2 \mathrm{in}$. diameter schedule 40 brass pipe. A $1 / 8$ in. pressure tap located $51 \mathrm{~mm}$ ( 2 in.) from the shower attachment end of the mounting pipe was provided to mount a water pressure gauge.

\subsubsection{Shower Spray Collection Device - Sector Rig}

The water spray from the shower was collected in the sector rig, figure 1 * located $1.9 \mathrm{~m}(6.5 \mathrm{ft})$ below the shower head; the sector rig was leveled on the test stand platform. The collection device with three annular channels each divided into six $60^{\circ}$ (pie shaped) sectors, was fabricated from $(12.5 \mathrm{~mm}$ and $6.2 \mathrm{~mm}$ thickness) plexiglass sheets. The outer diameter of $76.2 \mathrm{~cm}$ ( 30 in.) for the third annular ring was based upon the shower head cone angle specification in Federal Performance Specification WW-S-1913A [10]. The diameter of the innermost section, the $10.2 \mathrm{~cm}$ (4 in.) cylinder, was arbitrarily selected; it provides added attachment support for the radial divider pieces. Each annular channel was divided into sectors, $60^{\circ}$ apart, to obtain circumferential distribution data on the angular variability of the spray. The $60^{\circ}$ divisions were considered to be a reasonable value for peripheral measurement purposes, e.g., the use of $90^{\circ}$ elements was rejected since the quadrants would provide averaged collection data over too large a peripheral distance. Ultimately, a decision for $60^{\circ}$ or smaller divisions should be determined within a committee of a consensus standard group. Plastic graduated scales, $15.2 \mathrm{~cm}$ ( 6 in.) were

* A plastic pool was placed under the collector to collect and prevent excessively wide sprays and overflows from wetting the laboratory test area. 
permanently attached by a waterproof adhesive to a vertical side within each of the 19 compartments. The scales provided the depth level measurement by observation of the miniscus at the water surface on the scale for the water collected in each of the compartments. Alternative methods of measuring the depth of water and hence the volume in the water collection device are discussed in appendix B. In each sector, a drain hole was provided to remove the water after each test; stoppers were provided to plug the holes during testing.

\subsection{INSTRUMENTATION}

The shower head test instrumentation system was designed to monitor and record the important fluid flow parameters. The instruments and their location were also noted in figure 2. A list of equipment and their respective accuracies is presented in table 1 .

Data were recorded by means of an electronic data acquisition system (DAS) consisting of a multichannel data logger, eight bit microcomputer with as sociated floppy disk file storage, video terminal and impact printer. Signals from the turbine flow meter, flow switch, pressure transducer, and thermocouple were inputs to the data logger. The control interface of the data logger unit provided for transfer of data to the microcomputer. The computer was programmed to collect the raw data from the data logger, reduce the data, store the data on the floppy disks, and display the results on the system printer.

The water consumption and flow rate were measured by a residential type water meter and also by a separate turbine meter. The water meter provided an accurate means of determining the quantity of water used during each test. The turbine flow meter was installed in addition to provide direct digital display of the water flow rate. The unit also provided an analog output voltage directly proportional to the measured water flow rate and recorded by the data acquisition system.

The water temperature was monitored with a thermocouple inserted into the shower head water supply line, in contact with the water. The transducer values were displayed on a digital temperature indicator. The thermocouple was also connected to the DAS for automatic recording of the water temperature. The temperature indicator was primarily used to set the desired water temperature before a test, while the data logger recorded the temperature during a test. The water pressure at the shower head was measured by a mechanical gauge and a strain gauge type transducer connected to the pressure tap located on the mounting pipe. Both instruments had a pressure range of 0 to $689 \mathrm{kPa}$ ( 0 to $100 \mathrm{psi}$ ). The mechanical indicator gauge was used to set a nominal operating test pressure while the more accurate pressure transducer provided a more precise recorded measurement. Other methods of instrumentation are described in appendix $B$. 
The tests were conducted as follows:

1. The shower head was attached to the water supply mounting pipe and tested for leakage.

2. The mounting pipe and shower head assembly were carefully centered and aligned with a plumb line over the inner central zone of the water collection device to provide discharge in the vertical direction.

3. The water flow through the system was initiated by energizing the electrically operated solenoid valve.

4. Adjustment was made to the mixing valve to obtain the proper water temperature and then the needle valve was adjusted for the correct pressure.

5. The solenoid valve was closed to stop the water flow but retain the valve settings for the next test step. The water collected in the sector rig was drained. After draining, the holes were plugged with stoppers.

6. The numerical display on the water meter was recorded on the data sheet as the initial value. The toggle switch was closed to allow the computer to accept input from the flow meter, pressure transducer, and thermocouple.

7. The test was initiated. The solenoid control valve was opened to start the water flowing again and simultaneously start a laboratory type stop watch. The flow of water was continued until either one of the sectors reached a 75 percent fill level or at preselected time periods of 20,30 , or 60 seconds.

8. The flow rate and actual water temperature in the time interval were recorded on the data sheet. After the flow was terminated, the water meter reading was recorded as the final value. The total time (in seconds) of water flow was entered on the data sheet.

9. The total volume of water discharged through the shower head was obtained as the difference between the final and initial values on the water meter. The volume divided by the time of the test run provides an average flow rate value. The flow rate, indicated by the turbine meter, when multiplied by the time also provides the total water volume used.

10. The water level for each of the compartments of the water collection device were then recorded on the data sheet. The total quantity of water in all the sectors, determined by using the conversion factor from a calibration (volume curve vs scale reading) graph for each 
sector*, should equal the amount indicated by the water meter. For these tests, the accuracy of the total water used and calculated by summing the sector should agree within \pm 5 percent. The test should be repeated and observations carefully made to reduce errors and/or determine overspray if outside \pm 5 percent agreement.

To determine the effect of changing the alignment between the shower head and the mounting pipe, an additional test was carried out. Two pressures of $340 \mathrm{kPa}$ and $550 \mathrm{kPa}\left(50\right.$ and $80 \mathrm{psig}$ ) and only one temperature of $29.4^{\circ} \mathrm{C}$ $\pm 2.5^{\circ} \mathrm{C}\left(85 \pm 5^{\circ} \mathrm{F}\right)$ were selected. With the temperature conditions and one of the preselected pressures established and the mounting pipe and shower head aligned, the flow rate data and angular position of mounting pipe were obtained and were stored in the computer. The data input to the computer was then interrupted, the supply pipe position displaced to the limited or prescribed tilt and the water flow then reestablished. After a 30 second stabilization period, the pressure, flow rate, and temperature values were again stored in the computer for subsequent analysis.

On shower heads equipped with a manual spray adjustment, it was recognized that tests may be required to include determination of the effect of the adjustment setting over the range of pressures on the shower head flow rate and the distributions in the sectors. The recommended test procedure for measurement at various settings of the manual spray adjustment are presented in section 4.1.3.C.

Classification of shower heads into two groups is necessary; convenient designations are: (1) manufactured assemblies, and (2) modified retrofits. Subcategory designations were also necessary to distinguish the technique for controlling or regulating the flow rate as either a fixed orifice or deformable orifice. A fixed orifice shower head is essentially a rigid flow control element (restrictor) with one or more orifices which restricts the flow. A deformable orifice is fabricated from a pliable substance which alters the orifice dimensions as a result of variations in line pressure, thereby controlling the rate of flow. In addition, it is necessary to distinguish between nonadjustable and manually adjustable shower heads. Manually adjustable refers to the type of shower head construction where the spray stream (intensity, flow rate or cone angle) may be altered in use with a control device which is external (not requiring disassembly) and located within or outside the shower spray cone. Nonadjustable heads do not have external control capability. Table 2 indicates the seven types of shower heads selected for the laboratory tests and also indicates category designations for restrictors.

\subsection{DATA REDUCTION}

The data derived from the vertically aligned water distribution tests are listed in appendix $C$ for each shower head. Each data record contains three groups of tabulated results for one shower head; they are the sector compartment, water depth, and water volume for each temperature, pressure, and orientation of the shower head. The actual water volumes collected are shown;

* See appendix A for a method of calibration of the sector rig compartments. 
for comparisons the data have been normalized to a common 2 minute test period to provide a common base to facilitate comparisons for all tests. Generally, testing was completed within 1 minute and never extended beyond 2 minutes to avoid overflow. The equation utilized for determining the amount of water collected in individual compartment, adjusted for the 2 minute test period, is:

$$
Q=(B-C)(X)(Y) \text { liters }
$$

where:

$$
\mathrm{x}=\frac{120}{\mathrm{t}}
$$

and: $Q=$ water collected per compartment (liters)

$\mathrm{X}=$ normalization factor

$t=$ actual test duration (seconds)

$C$ = initial water level reading ( $\mathrm{mm})$

$B=$ final water level reading $(\mathrm{mm})$

$\mathrm{Y}=$ calibration factor, appendix B (liters per mm of water depth)

From this detailed set of data, the radial and circumferential water distribution patterns by compartments may be examined.

The second data group presents the quantity of water collected in each annular channel for the selected test conditions. These results were obtained from the first data group by summing the individual sector water volumes for each ring. This group of data essentially represents the radial distribution of water (independent of peripheral distribution) and can be used to determine the shower spray cone angle (upper limit values only since the radial distribution variation is averaged over each radial increment).

The total quantity of water for each test condition is tabulated in the third group of data. Listed separately in this group are the water volumes collected, based on the sum of the sectors and water volume based upon the time interval and flow rate from the meter reading. The accuracy is indicated by the percent difference based upon the difference of the metered value and the sector sum value. 


\subsection{WATER DISTRIBUTION}

\subsubsection{Radial and Circumferential Water Distribution}

The tabulations of the spray distribution pattern results for the seven shower heads tested are listed in tables 3, 4, and 5. These tables present the data collected from the distribution tests at three pressures, 140, 340, and $550 \mathrm{kPa}(20,50$, and $80 \mathrm{psig})$ and two temperatures $29.4^{\circ} \pm 2.5^{\circ} \mathrm{C}$ and $40.5^{\circ} \mathrm{C} \pm$ $2.5^{\circ} \mathrm{C}\left(85^{\circ} \mathrm{F} \pm 5^{\circ} \mathrm{F}\right.$ and $\left.105^{\circ} \mathrm{F} \pm 5^{\circ} \mathrm{F}\right)$. Examination of the results, presented in the tables as liters of wate $\bar{r}$ collected in each sector (normalizing all results to a common 2 minute flow period), illustrates the wide variation in spray distribution patterns among the sampled low-flow shower heads. Figures 3 and 4 present the distribution patterns for the seven shower heads obtained from distribution patterns among the sampled low-flow shower heads. Figures 3 and 4 presents the distribution patterns for the seven shower heads obtained from the sector rig for two pressures at one temperature. Within the same ring "a" in figure 3 , the mean values in the sectors vary by $3: 2$, whereas at the higher pressure in figure 4 the mean of the " $a$ " sectors vary by $2: 1$ around the periphery. In ring "b", except for sector 6 , the mean is nearly constant. At the higher pressure a greater quantity of water is collected in ring " $a$ " as compared with the low pressure case; that indicates a reduction in cone angle with increased pressure. Also, the greater total volume of water can be noted at the higher pressure. Ring "c", with diameter greater than $75 \mathrm{~cm}$, collects very little water, while the central cylinder, $7.5 \mathrm{~cm}$, has a mean value either greater than or comparable to the values in the " $a$ " and " $b$ " rings. The values shown from this limited test sample indicate that a reference average basis for establishing relative comparisons between shower heads can be developed from a large enough sample of shower head tests. The test method primarily indicates whether excessive concentration in one sector occurs (compared with others) and if considerable wetting of the shower stall (or walls) may occur. A broader based statistically averaged data set, from a very large number of sample shower heads, would indicate the variability of water distribution deliverable from currently manufactured shower heads. The distribution pattern would establish a common basis for comparisons (leading to ratings based upon departure from the mean including a tolerance on the performance) for all types of shower heads.

The amount of water collected in each compartment provides for the derivation of another measure of shower head performance, an intensity distribution. The intensity distribution term provides an indication of the distribution of water flow volume per unit area per unit time. From the volumetric rate of water collected in any compartment, the value of volumetric rate per unit area (across the surface area of the collector) may be computed; it is an indicator (on the average, over the area of the specific compartment) of the rate at which the water spray (across the horizontal plane above the sector rig) enters that region. Low values indicate a "soft" shower and larger values imply a "hard" shower. Intensity distribution mapping over the wetted areas may be useful in establishing "effectiveness" ratings since it is an improved measure of distribution as compared to the direct measurement of the collected volume 
in each compartment. Since the surface area of sector compartments increase from " $a$ " to " $b$ " to " $c$ " rings, the values of intensity distribution derived from the collected volumes in figures 3 and 4 would decrease in inverse proportion to the increased areas. This measure may also become a useful parameter in further research for subjective response on comfort characteristics, or associated with a method for determining the effectiveness of the removal of surface (soap or oil) films.

\subsubsection{Measured and Metered Water}

Figures 5A and 5B present comparisons of the total measured water based upon the collection device (summed) values vs metered water used in three separate tests. Measured water is the total quantity of water collected in all the compartmencs of the sector rig. Metered water is the total quantity of water obtained from the turbine meter rate over the test time interval. Figure 5A presents data from tests conducted with warm water on three different shower heads, and figure 5B from tests conducted with hot water. The ideal relationship between the two quantities is indicated by the straight line. Although there is some scatter of data in these representative comparisons, the agreement shown is good. The two quantities are not necessarily equal; a discrepancy between the two quantities could be attributed to the shower spray water falling outside the collection device. The metered water readings should always be more exact (with a calibrated meter) than the sum of the measured compartmental water volumes. Discrepancies in reading the individual scales for the depth of the water in a compartment contributes to the error in the summation; the calibration procedure of appendix A will reduce errors. Water outside the outer ring cannot be measured by the distribution device but may be observed and noted during the test (and could be collected). Differences in values greater than \pm 5 percent between the rig collection and meter readings should be repeated and observations carefully made to reduce errors and/or determine over spray. Figure 5A, illustrates data for volume collected by summation beyond 5 percent limits. To reduce or eliminate the error in measuring the water depth in individual sector compartments by physically reading the scales, other instrumentation, such as pressure transducers or water manometers, as indicated in appendix B, can be substituted. Such instruments would improve measurement accuracy, reduce the time needed to run the tests, and provide a method by which the tests could be computerized.

\subsection{SHOWER HEAD ORIENTATION}

The effect of shower head orientation on the shower head flow rate-pressure relationship is shown in table 6 . The results were obtained from tests where the angular displacement of the shower head mounting pipe was set to the maximum obtainable offset determined by the physical limits of the shower head. An examination of these data reveals that there appears to be little or no significant change in the water flow rate or pressure drop between the aligned and offset conditions. In this test series, the large changes cited in the California study [4] (test series of a very large variety of shower heads) were not found. The California study revealed that with some shower 
heads (ball type) the flow rate changed significantly when the shower heads were swiveled. The number of shower heads in the NBS tests was small, since the subject of the investigation was the method of testing and was not intended to be a test program for evaluation of shower heads.

\subsection{WATER FLOW RATE VS PRESSURE}

Appendix $C$ includes the data on the volume of water collected at the three test pressures, 140,340 , and $550 \mathrm{kPa}(20,50$, and $80 \mathrm{ps} 1)$. These data are average values calculated from the total quantity of water used during the test time period and normalized to the common basis of a 2 minute test

duration. The data for the total collected volumes can then be converted into flow rates for the adjusted time period and compared. Since the distribution pattern tests are primarily intended to provide data at a limited number of selected pressures, the data for the the flow rate pressure dependency over the entire range of possible pressures should be determined separately. A supplementary series of tests was performed with the turbine meter in the water supply line to obtain data points for determination of the dependence of flow rate on pressure.

The water flow rate vs pressure data at the two test temperatures are shown in figures $6 \mathrm{~A}$ and $6 \mathrm{~B}$ for six of the seven tested shower heads. Although these tests indicate little shower head water flow rate dependency on temperature, the results of the larger study [4] indicated significant changes for several shower heads.

The flow rate pressure dependency in some cases shows undesirable variations of flow rate with changes in pressure. An ideal shower head would be one with very flat response curve to changes in pressure. For two shower heads, after a rise in flow rate with pressure, the curves are flat (figures $6 \mathrm{~A}^{-1}$ and $6 \mathrm{~B}-2)$; a trending downward after a peak flow rate occurs with two others (figures $6 \mathrm{~A}-2$ and 3 ). The other shower heads display a continuing rise in flow rate with pressure, a characteristic usually associated with a nonwater saving device where flow rate is proportional to the square root of pressure drop. However the highest flow rate in those tests were close to 14 liters/min $(3.5$ to $4 \mathrm{gpm}$ ) and may be regarded as a watersaving shower head. The lower flow rates at lower pressure can result in an unsatisfactory shower based upon user requirements [4].

The flow rate variations with pressure for three restrictor inserts in a conventional shower head are shown in figure 7 . The data indicate that the modified performance with reduced flow restrictors may not provide sufficient reductions in water consumption. The hydraulic discharge characteristics are dependent upon other parameters (e.g., geometrical distribution of orifices, internal flow channels) as well as the design of the restrictor. 


\subsection{TEST METHOD GUIDES}

The requirements for shower head tests to determine the hydraulic characteristics should include the following proposed elements:

\subsubsection{Shower Head Test Configuration}

An instrumented shower head test configuration, similar in design to that illustrated in figure 2, should be utilized. The minimum test configuration will consist of:

1. A straight shower head mounting arm (pipe) consisting of $1 / 2$ in. schedule 40 brass pipe at least $1 \mathrm{ft}$ long.

2. A pressure tap $2-4 \mathrm{~mm}(1 / 16 \mathrm{in.}-1 / 8 \mathrm{in.})$ in diameter positioned 25-50 mm (1-2 in.) from the bottom of the mounting arm (pipe).

3. A means of providing rigid support for the shower head to maintain it in a vertical position.

4. A method of changing the angular orientation of the centerline of the mounting arm (pipe) with respect to the shower head (to simulate tilt of the shower head).

5. A water collection device located $1.9 \mathrm{~m}(6.5 \mathrm{ft})$ below the water exit plane of the water supply connecting pipe (or to the test shower head). In addition, the collection device provided is to be comparable in size and configuration to figure 1. The centerline of the collection device is to be located directly below the centerline of the test shower head.

6. A water supply system capable of delivering 30 lpm ( $8 \mathrm{gpm}$ ) of water at $690 \mathrm{kPa}$ (100 psig) over a range of temperatures from the cold supply to $29.5^{\circ} \mathrm{C} \pm 2.5^{\circ} \mathrm{C}\left(105^{\circ} \mathrm{F} \pm 5^{\circ} \mathrm{F}\right)$.

\subsubsection{Test Instrumentation}

Sultable instrumentation is required to set, monitor, and measure the water flow rate, temperature, and pressure before and during shower head tests. The following is a description of the instrumentation required for a minimum acceptable test configuration.

1. Water consumption will be monitored by a low range (typical) 0-60 \&pm (0-15 gpm) water meter.

2. Water flow rate will be measured by a direct indicating instrument, such as the turbine meter-signal conditioner used in this study, with a minimum accuracy of \pm 1 percent full scale and resolution of $0.4 \mathrm{lpm}$ $(0.1 \mathrm{gpm})$ or better. 
3. Water temperature is to be measured to within $\pm 0.6^{\circ} \mathrm{C}\left( \pm 1^{\circ} \mathrm{F}\right)$ of specifled test temperature.

4. Water pressure, to be measured at the location specified in section 4.1 .1 , is to be measured by a pressure gauge or transducer with a minimum accuracy of \pm 5 percent full scale and a resolution of $7 \mathrm{kPa}(1.0 \mathrm{psi})$.

5. Water level measurements in the water collection device will be made by graduated scales, pressure transducers, or manometers. Accuracy of the transducers or manometers may not be less than the graduated scales ( 1 percent of full scale).

6. A timer, accurate to 0.1 second or better, will be required to record the test duration.

\subsubsection{Testing and Data Recording}

Utilizing a test apparatus configuration with instrumentation which meets the specifications outlined in the previous two sections, two types of tests, water distribution and pressure-flow rate, will be performed on each shower head. Shower heads with no mechanical provisions for adjustment of the spray stream are to be examined using test procedures described in A and B below. The shower heads with adjustable spray streams are to be tested using procedures $A$, $B$, and $C$.

\section{A. 1 Water Distribution}

This procedure is designed to provide data for radial and circumferential water distribution of the shower head spray pattern. Appendix $C$ illustrates typical test data requirements. The hot water range of temperature should be $29.5^{\circ} \mathrm{C} \pm 2.5^{\circ} \mathrm{C}\left(105^{\circ} \mathrm{F}+5^{\circ} \mathrm{F}\right)$ and warm $40.6^{\circ} \mathrm{C} \pm 2.5^{\circ} \mathrm{C}\left(85^{\circ} \mathrm{F}+5^{\circ} \mathrm{F}\right)$. The tests w111 be run at three pressures, 140,340 , and $550 \mathrm{kPa}(20, \overline{50}, 80 \mathrm{psig})$. The two positions for the mounting pipe, vertical and offset, are 1llustrated in figure 2. The vertical position is defined as that arrangement where the head is always vertical and the mounting pipe is aligned with the vertical position of the shower head. The offset position is where the pipe is placed to the maximum swiveled position relative to the shower head.

\section{A.2 Test Procedure}

1. Level the water collection device. Mount the shower head to the mounting pipe and secure the pipe in the vertical position. Check for water leakage by pressurizing. Use a plumb line to center the water collection device beneath the shower head.

2. Run water through the system and shower head by opening the solenoid, or quick opening valves, and adjust the pressure and temperature to their preselected values. Orient the shower head so that the resultant spray pattern on the water collection device is also visually centered (and 
check again with plumbline). This can be accomplished by viewing the shower from two locations $90^{\circ}$ apart and then making the required position corrections. Clamp the shower head in position to prevent any further movement.

3. Turn the water off and empty the water collection device.

4. Plug the drain holes in the water collection device. For each compartment, record the water level if not completely drained (tare correction).

5. Record the water meter reading.

6. Open the solenoid or quick opening valve, simultaneously start the timer.

7. Stop the water flow and timer when any of the following occurs:

a. 120 seconds have elapsed,

b. any one sector is approximately 75 percent full.

8. Record the following data:
a. water meter reading,
b. elapsed time,
c. water levels in each sector compartment,
d. notation if overspray occurs.

9. Repeat the procedure for other pressure, temperatures, and mounting pipe positions.

The above description outlines the procedure proposed for use with the test configuration similar in design to that presented in this report. The basic principles underlying this procedure would be applicable to other configurations such as those discussed as alternative methods and illustrated in appendix $B$ with appropriate changes in the data collection and recording procedures.

\section{B. Shower Head Flow Rate - Pressure Test}

This section deals with the method to be used to collect data on the flow rate-pressure relationship of any type of shower head independent of the collection device. Each shower head will be tested at two temperatures, $29.5^{\circ} \mathrm{C}$ $\pm 2.5^{\circ} \mathrm{C}\left(85^{\circ} \mathrm{F}+5^{\circ} \mathrm{F}\right)$ and $40.6^{\circ} \mathrm{C}+2.5^{\circ} \mathrm{C}\left(105^{\circ} \mathrm{F} \pm 5^{\circ} \mathrm{F}\right)$, and over a pressure range of 70 to $690 \mathrm{kPa}$ (10 to $100 \mathrm{psig}$ ). Starting at $10 \mathrm{psig}$ repeat the tests in increments of $10 \mathrm{psi}$ until $100 \mathrm{psig}$ is attained, then repeat downscale to 10 psig. That provides 19 data points for an individual shower head. The procedure required is outlined below: 
1. Mount the shower head and position the mounting pipe in the vertical position.

2. Run water and set the initial pressure point; adjust to the required temperature.

3. Record the pressure and flow rate.

4. Repeat procedure for the other pressures and temperatures.

\section{Manua1ly Adjustable Spray Head Test}

The test method outlined in this section applies to those types of shower heads which employ a mechanism for manual adjustment of the spray stream without device disassembly. Each shower head is to be tested at two temperatures, $29.5^{\circ} \mathrm{C}+5^{\circ} \mathrm{C}\left(85^{\circ} \mathrm{F}+5^{\circ} \mathrm{F}\right)$ and $40.6^{\circ} \mathrm{C}+2.5^{\circ} \mathrm{C}\left(105^{\circ} \mathrm{F}+5^{\circ} \mathrm{F}\right)$ over a pressure range of 70 to $690 \overline{\mathrm{kPa}}$ (10 to $100 \mathrm{psig})$ in $70 \mathrm{kPa}(1 \overline{0} \mathrm{psi}$ ) increments. At each pressure point, three and up to six data points are to be collected corresponding to a different setting of the spray adjustment mechanism. of these (three to six points) two will be end points for maximum fine and coarse spray and the others shall be intermediate settings. A brief description of the test procedure is given below:

1. Mount shower head and secure mounting pipe in vertical position.

2. Adjust the shower spray with water running for maximum fine or coarse.

3. Set water pressure and adjust temperature.

4. Record pressure and flow rate.

5. While maintaining selected pressure, adjust spray mechanism and record the corresponding flow rate.

6. Repeat step 5 for at least three and up to six shower head spray adjustment settings as indicated above.

7. Repeat entire procedure for the other required pressures and temperatures.

\subsubsection{Results}

The test results for each shower head are derived from the data collected utilizing the procedures $A, B$, and $C$ outlined in the previous section. The scheme for reducing the data is outlined in sections 2 and 3 of this report.

The results of the tests are recorded in a form similar to that illustrated in appendix $C$, and should include the radial and angular water distribution patterns. These tables provide information so that additional shower head spray characteristics, such as flow rate (cone angle, over spray and intensity 
distribution) may be calculated. The flow rate data obtained by this procedure is supplementary to the detail from procedure $B$. The cone angle may be established by examining the shower head spray radial distribution results. The value represents only an approximation because the radial resolution of the water collection device is very low (radially spaced inserts placed into the sectors are required for finer resolution). The cone angle can alternatively be obtained for the shower spray based upon observations or photographic means, or measuring the maximum wetted diameter at a fixed location below the shower head. Guidelines for determining the acceptable values for cone angles are unknown in terms of user spray pattern requirements. Overspray water that falls outside the prescribed cone angle or water collection matrix may be determined from the reduced test data, appendix $C$. The cone angle measurement provides an indication of the size of wetted surface area covered by the shower spray.

The average water intensity distribution can be defined as the quantity of water per unit of time and area entering an individual compartment, sector ring or other zone. The intensity distribution can be useful in describing the spray symmetry and could imply a measure of the stream strength (or force) as a comfort indicator or possibly as an average velocity to shear away the soap suds film.

The results from test procedure $B$ contain information to adequately describe the shower head variability for the flow rate-pressure relationship. A maximum flow rate can be specified for water saving requirements and the variability of the flow rate with pressure may be prescribed, within some limit value, for evaluating or rating the performance of the shower head. Caution must be exercised to prevent an undesirable flow rate requirement which is not acceptable for the user and intended functions.

The results from the test procedure $C$ are collected only from shower heads with user adjustable spray patterns. From the data collected and curves plotted the maximum flow rate for any test pressure may be found. Analysis from the additional data for the various setting is required to determine the maximum flow rate-pressure relationship for the shower head. Further evaluation of the performance of a shower head at any given set of pressure-temperature conditions over the control range may be required. 


\section{CONCLUSIONS}

The test equipment and evaluation method for low-flow shower head water spray, distribution and flow rate was developed to provide performance requirements not previously considered. The recommended shower head test method was performed with relative ease in the laboratory; the test configuration requires the usual instrumentation and measurement methods available in hydraulic laboratories. The use of the word "shower head" in all cases is intended to include flow-restrictor-shower head retrofit combinations. The water collection device (sector rig) utilized in this study is required for the additional performance evaluation of water distribution from shower heads which effectively quantifies the amount of water distributed across the surface of the collection device. The qualification noted is that the configuration adopted appears to be minimally acceptable; alternate designs for the collection device should be considered in developing a consensus standard. 
6. REFERENCES

1. President Carter, "Water Conservation Policy," July 1978.

2. Miller, J., The Potential for Energy Savings Through Reductions in Hot Water Consumption, Proceedings of Conference on Water Conservation and Sewage Flow Reduction with Water Saving Devices, Pennsylvania State University office of Water Research and Technology, July 1975.

3. Fulton, N. R., "Elmhurst, Illinois," Division of Water Resource, Illinois Department of Transportation, Presentation at Plenary Session II, EPA National Conference on Water Conservation and Municipal Wastewater Flow Reduction, November 1978.

4. A Pilot Water Conservation Program, Final Report, March 1978, Bulletin 191, State of California, Department of Water Resources.

5. Water Conservation in California, State of California, Department of Water Resources, Bulletin 198, May 1976.

6. Milne, M., Residential Water Reuse, California Water Resources Center, University of California/Davis, Report No. 46, September 1979.

7. HR 9363 Water Efficiency Labeling Act, Introduced by Congressman L. Panetta (CA)

8. Englund, M., Hallberg, G., Space Requirements for Showers, The Swedish Council for Building Research, Stockholm, Sweden, December 11, 1979, ISBN 91-540-3105-2.

9. FS-WW-S-1913A Shower Head, Ball Joint Integral Flow Control, October 1977 , Federal Specification, Commanding officer (Code 512), the Naval Publications and Forms Center, 5801 Tabor Avenue, Philadelphia, PA.

10. Plumbing Fittings, Canadian Standards Association, GSA Standard B125-1975, October 1975.

11. Elder, J., State of the Art Summary of Incentives for Residential Water Conservation, NBSIR 80-2119, October 1980 . 
Table 1. List of Laboratory Instrumentation

\section{Instrument}

Thermostatic Mixing Value

Throttling Valve

Water Meter

Temperature Indicator

Turbine (Transducer) Flow Meter

Flow Indicator (Signal Conditioner)

Flow Switch

Solenoid Valve

Pressure Gauge

Pressure Transducer

Data Logger

Computer (Micro)
Figure 2

Reference

1

2

3

4

5

6

7

8

9

10

11

12
Nominal

\% Accuracy

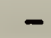

1\% F.S.

$\pm 1^{\circ} \mathrm{F}$

$1 \%$ F.S.

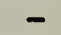

5\% F.S.

$1 \%$ F.S. 
Table 2. Shower Head/Flow Restrictor Classifications

\section{Shower Heads}

\begin{tabular}{|c|c|c|c|c|c|}
\hline Type & NBS & Rated & Type & INBS & Rated \\
\hline Fixed Orifice & Code & (flow rate) & Deformable Orifice & Code & (flow rate) \\
\hline \multirow[t]{2}{*}{$\begin{array}{l}\text { Non-Adjustable } \\
\text { Head }\end{array}$} & F1 & $\mathrm{N} / \mathrm{A}^{*}$ & \multirow[t]{2}{*}{$\begin{array}{l}\text { Non-Adjus table } \\
\text { Head }\end{array}$} & E1 & $\begin{array}{l}11.4(2 / \mathrm{m}) \\
(3.0 \mathrm{gpm})\end{array}$ \\
\hline & $\mathrm{H} 1$ & $N / A^{*}$ & & $\mathrm{OA}$ & $\begin{array}{l}11.4(2 / \mathrm{m}) \\
(3.0 \mathrm{gpm})\end{array}$ \\
\hline \multirow{2}{*}{$\begin{array}{l}\text { Manually } \\
\text { Adjus table } \\
\text { Head }\end{array}$} & \multirow{2}{*}{ A3 } & \multirow{2}{*}{$\begin{array}{l}9.5(\mathrm{l} / \mathrm{m}) \\
(2.5 \mathrm{gpm})\end{array}$} & \multirow[t]{2}{*}{$\begin{array}{l}\text { Manually Adjustable } \\
\text { Head }\end{array}$} & $\mathrm{Cl}$ & $\mathrm{N} / \mathrm{A}^{*}$ \\
\hline & & & & G3 & $\begin{array}{l}11.4(\mathrm{l} / \mathrm{m}) \\
(3.0 \mathrm{gpm})\end{array}$ \\
\hline
\end{tabular}

* Not applicable

Insert Flow Restrictors**

\begin{tabular}{|l|l|l|c|}
\hline \multicolumn{2}{|c|}{ Rigid } & \multicolumn{2}{c|}{ Deformable } \\
\hline Shower Head & Rated & Shower Head & Rated \\
\hline Non-Adjustable Head & N/A & Non-Adjustable Head & N/A \\
\hline Manually Adjustable Head & & Manually Adjustable Head & \\
\hline
\end{tabular}

** Not included in distribution pattern tests

1 Varies with pressure

2 Flow rate variations with pressure may occur 
Table 3. Water Distributions in Sector Compartments at $138 \mathrm{kPa}$ WARK UATER TEST RESULTS ( 7 TESTS) PALSSURE $=138 . \mathrm{KPz}$

VOLURA OE VITER CAUGHT (liters)

\begin{tabular}{|c|c|c|c|c|}
\hline SECTOR & หINIหUת & MEAK & Muxikon & STR. DEV. \\
\hline 10 & .000 & 1.520 & 3.916 & 1.555 \\
\hline ia & .234 & 1.612 & 3.885 & 1.361 \\
\hline 16 & .095 & .737 & 1.230 & .363 \\
\hline Ic & .000 & .173 & 1.071 & .370 \\
\hline 32 & .121 & 1.138 & 3.860 & .912 \\
\hline 36 & .086 & .897 & 1.533 & .514 \\
\hline $3 c$ & .000 & .010 & .073 & .025 \\
\hline 32 & .211 & 1.106 & 2.232 & .705 \\
\hline $3 b$ & .000 & .788 & 1.683 & .657 \\
\hline $3 c$ & .000 & .010 & .000 & .000 \\
\hline 12 & .393 & .9190 & 1.769 & .525 \\
\hline 16 & .000 & .781 & 1.196 & .581 \\
\hline Ic & .000 & .030 & .143 & .056 \\
\hline 52 & .393 & 1.502 & 2.653 & .900 \\
\hline 56 & .000 & .877 & 2.032 & .779 \\
\hline $5 c$ & .000 & .020 & .143 & .050 \\
\hline 61 & .025 & 1.646 & 1.716 & 1.490 \\
\hline $6 b$ & .000 & 2.082 & 1.542 & 1.511 \\
\hline $6 \mathrm{c}$ & .000 & .010 & .071 & .029 \\
\hline
\end{tabular}

HOT UATER TEST BESULTS ( 6 TESTS) PLESSURE $=138$. KPE

VOLUAH OF GATER CAUGhT (1iters)

\begin{tabular}{|c|c|c|c|c|}
\hline SECTOR & Mikitus: & MEM & masinu & STD. DEV. \\
\hline 00 & .000 & 1.257 & 3.413 & 1.479 \\
\hline 18 & .000 & 1.490 & 2.889 & 1.125 \\
\hline Ib & .189 & .733 & 1.751 & .513 \\
\hline Ic & .000 & .071 & .397 & .130 \\
\hline 22 & .194 & 1.968 & 2.475 & .881 \\
\hline $2 b$ & .192 & .787 & 1.312 & .462 \\
\hline $3 c$ & .000 & .085 & .437 & .160 \\
\hline 33 & .073 & 1.169 & 2.135 & .773 \\
\hline 36 & .000 & .584 & 1.117 & .686 \\
\hline $3 c$ & .000 & .000 & .214 & .000 \\
\hline la & 319 & 1.097 & 2.162 & .671 \\
\hline tb & .000 & .647 & 1.543 & .414 \\
\hline 16 & .000 & .012 & .214 & .027 \\
\hline 52 & .025 & 1.572 & 3.046 & 1.068 \\
\hline 56 & .000 & .839 & 2.078 & .757 \\
\hline Ic & .000 & .048 & .211 & .079 \\
\hline 62 & .000 & 1.539 & 3.734 & 1.282 \\
\hline $6 b$ & .000 & 3.098 & 1.163 & 1.569 \\
\hline oc & .000 & .107 & .121 & .164 \\
\hline
\end{tabular}


Table 4. Water Distributions in Sector Compartments at $344 \mathrm{kPa}$

GARM UATER TEST IESULTS ( 7 TESTS) PAESSURE $=344.1 \mathrm{PZ}$

VOLUSA OE VITER CAUGHT (IIters)

\begin{tabular}{|c|c|c|c|c|}
\hline SECTOR & MIRIKOA & MEAN & MAX ImU: & STD. DEV. \\
\hline 10 & .000 & 2.188 & 4.244 & 1.896 \\
\hline 12 & .299 & 2.380 & 5.778 & 1.598 \\
\hline ib & .000 & .781 & 1.514 & .539 \\
\hline ic & .000 & .071 & .357 & .127 \\
\hline 33 & .121 & 2.277 & 9.658 & 1.216 \\
\hline $2 b$ & .000 & .952 & 2.300 & .657 \\
\hline $2 c$ & .000 & .042 & .218 & .076 \\
\hline 32 & .315 & 1.761 & 2.126 & .656 \\
\hline $3 b$ & .000 & .708 & 1.496 & .679 \\
\hline $3 c$ & .000 & .000 & .000 & .000 \\
\hline 42 & .319 & 1.467 & 2.918 & .863 \\
\hline $4 b$ & .000 & .821 & 1.870 & .655 \\
\hline 4c & .000 & .020 & .143 & .050 \\
\hline 52 & .197 & 1.814 & 3.243 & .961 \\
\hline 36 & .000 & $.84 i$ & 1.755 & .688 \\
\hline 50 & .000 & .041 & .286 & .100 \\
\hline sa & .000 & 1.015 & 3.537 & 1.313 \\
\hline $6 b$ & .000 & 2.190 & 5.678 & 1.935 \\
\hline bc & .000 & .245 & 1.500 & .518 \\
\hline
\end{tabular}

HOT VATER TEST RESULTS ( 7 TESTS) PRESSURE $=344 . \mathrm{kPZ}$

VOLURA OE UATER CAUGHT (liters)

\begin{tabular}{|c|c|c|c|c|}
\hline SECTOR & MIMIKU: & MEAN & MarIKUS & STD. DEV. \\
\hline 00 & .000 & 2.489 & 6.698 & 2.381 \\
\hline 12 & .371 & 2.491 & 5.178 & 1.699 \\
\hline 16 & .000 & .588 & 1.119 & .168 \\
\hline 16 & .000 & .102 & .500 & .178 \\
\hline 22 & .364 & 2.125 & 1.561 & 1.241 \\
\hline $2 b$ & .000 & .685 & 1.533 & .538 \\
\hline 20 & .000 & .094 & .291 & .127 \\
\hline 32 & .412 & 1.771 & 2.523 & .688 \\
\hline $3 b$ & .000 & .581 & 1.309 & .589 \\
\hline $3 c$ & .000 & .051 & .286 & .099 \\
\hline 12 & .197 & 1.128 & 2.751 & .962 \\
\hline 16 & .000 & .721 & 1.776 & .661 \\
\hline Ic & .000 & .031 & .214 & .075 \\
\hline 52 & .000 & 1.916 & 3.734 & 1.277 \\
\hline $5 b$ & .000 & .877 & 1.893 & .759 \\
\hline Sc & .000 & .071 & .386 & .115 \\
\hline 62 & .000 & 1.853 & 3.636 & 1.259 \\
\hline $6 b$ & .000 & 1.595 & 1.163 & 1.507 \\
\hline ic & .000 & .255 & 1.571 & .542 \\
\hline
\end{tabular}


Table 5. Water Distributions in Sector Compartments at $551 \mathrm{kPa}$

VARH GATER TEST RESULTS ( 7 TESTS) PRESSURE $=551 . \mathrm{KPZ}$

VOLUSA OE VATER CAUGHT (liters)

\begin{tabular}{|c|c|c|c|c|}
\hline SECTOR & MIкIRUn & KEN & Maxinur & STO. DEV. \\
\hline 10 & .000 & 1.322 & 3.780 & 1.495 \\
\hline 11 & .299 & 3.266 & 7.372 & 2.405 \\
\hline 16 & .000 & .791 & 1.514 & .986 \\
\hline 16 & .000 & .184 & .786 & .270 \\
\hline 23 & .121 & 2.433 & 6.017 & 1.679 \\
\hline $2 b$ & .000 & .726 & 1.533 & .470 \\
\hline $2 c$ & .000 & .031 & .146 & .053 \\
\hline 32 & .315 & 1.716 & 2.523 & .707 \\
\hline 36 & .000 & .641 & 1.102 & .625 \\
\hline $3 c$ & .000 & .000 & .000 & .000 \\
\hline 12 & .393 & 1.149 & 3.046 & .814 \\
\hline 16 & .000 & .741 & 1.543 & .593 \\
\hline 16 & .000 & .010 & .143 & .025 \\
\hline 52 & .216 & 1.871 & 1.618 & 1.347 \\
\hline 56 & .000 & .805 & 1.755 & .699 \\
\hline $5 c$ & .000 & .010 & .143 & .025 \\
\hline 63 & .000 & 2.667 & 6.289 & 2.232 \\
\hline $6 b$ & .000 & 2.731 & 8.327 & 2.551 \\
\hline 10 & .000 & .265 & 1.286 & .435 \\
\hline
\end{tabular}

HOT UATER TEST RESULTS ( 7 TESTS) PRESSURE $=551 . \mathrm{Kl2}$

VOLUSA OE GATER CAUGAT (liters)

\begin{tabular}{|c|c|c|c|c|}
\hline SECTOR & MIKIKU: & MEAK & masinur & STD. DEV. \\
\hline 00 & .000 & 2.119 & 6.830 & 2.321 \\
\hline 12 & .374 & 2.900 & 7.571 & 2.272 \\
\hline 16 & .000 & .635 & 1.325 & .412 \\
\hline ic & .000 & .071 & .357 & .127 \\
\hline 22 & .364 & 2.381 & 6.114 & 1.735 \\
\hline 26 & .000 & .774 & 1.533 & .58 \\
\hline $2 c$ & .000 & .094 & .291 & .11 \\
\hline 32 & .509 & 1.885 & 3.688 & \\
\hline $3 b$ & .000 & .561 & 1.215 & .55 \\
\hline $3 c$ & .000 & .071 & .286 & .1 \\
\hline 12 & .172 & 1.484 & 3.537 & 1.05 \\
\hline 96 & .000 & .788 & 1.823 & .71 \\
\hline 46 & .000 & .031 & .211 & \\
\hline 52 & .049 & 1.930 & 3.734 & 1.18 \\
\hline 56 & .000 & .686 & 1.755 & \\
\hline sc & .000 & .051 & .357 & .12 \\
\hline 63 & .000 & 2.211 & 1.520 & 1.60 \\
\hline $6 b$ & .000 & 1.595 & 4.921 & \\
\hline 60 & .000 & .275 & 1.571 & \\
\hline
\end{tabular}


Table 6. Shower Head Orientation Tests Results

\begin{tabular}{|c|c|c|c|c|}
\hline \multirow{2}{*}{ Shower Head } & \multicolumn{2}{|c|}{ Normal Position (Aligned) } & Extreme Shower & \multirow{2}{*}{$\begin{array}{c}\text { Head Adjustment } \\
\text { Flow } \\
(\mathrm{gpm})\end{array}$} \\
\hline & $\begin{array}{c}\text { Pressure } \\
\text { (psi) }\end{array}$ & $\begin{array}{l}\text { Flow } \\
(\mathrm{gpm}) \\
\end{array}$ & \begin{tabular}{c|}
$\begin{array}{c}\text { Pressure } \\
\text { (psi) }\end{array}$ \\
\end{tabular} & \\
\hline \multirow[t]{2}{*}{ A3 } & 78.5 & 1.29 & 78.4 & 1.32 \\
\hline & 50.0 & 0.97 & 49.0 & 0.94 \\
\hline \multirow[t]{2}{*}{$\mathrm{Cl}$} & 79.9 & 1.95 & 79.1 & 1.90 \\
\hline & 49.8 & 1.81 & 50.1 & 1.83 \\
\hline \multirow[t]{2}{*}{ E1 } & 79.9 & 2.46 & 82.4 & 2.36 \\
\hline & 50.5 & 2.33 & $51 \cdot 1$ & 2.34 \\
\hline \multirow[t]{2}{*}{ F1 } & 77.9 & 2.65 & 77.2 & 2.61 \\
\hline & 49.4 & 2.09 & 48.7 & 2.08 \\
\hline \multirow[t]{2}{*}{ G1 } & 79.0 & 2.75 & 80.3 & 2.71 \\
\hline & 49.1 & 2.98 & 49.7 & 2.97 \\
\hline \multirow[t]{2}{*}{$\mathrm{Hl}$} & 78.7 & 3.58 & 74.7 & 3.55 \\
\hline & 50.0 & 2.79 & 48.2 & 2.83 \\
\hline \multirow[t]{2}{*}{$O A$} & 79.6 & 2.83 & 81.0 & 2.78 \\
\hline & 50.3 & 2.97 & 50.7 & 2.96 \\
\hline
\end{tabular}

Conversions:

$$
\begin{aligned}
& \text { psi } \times 6.89=\mathrm{kPa} \\
& \text { gpm } \times 0.063=\ell / \mathrm{sec}
\end{aligned}
$$



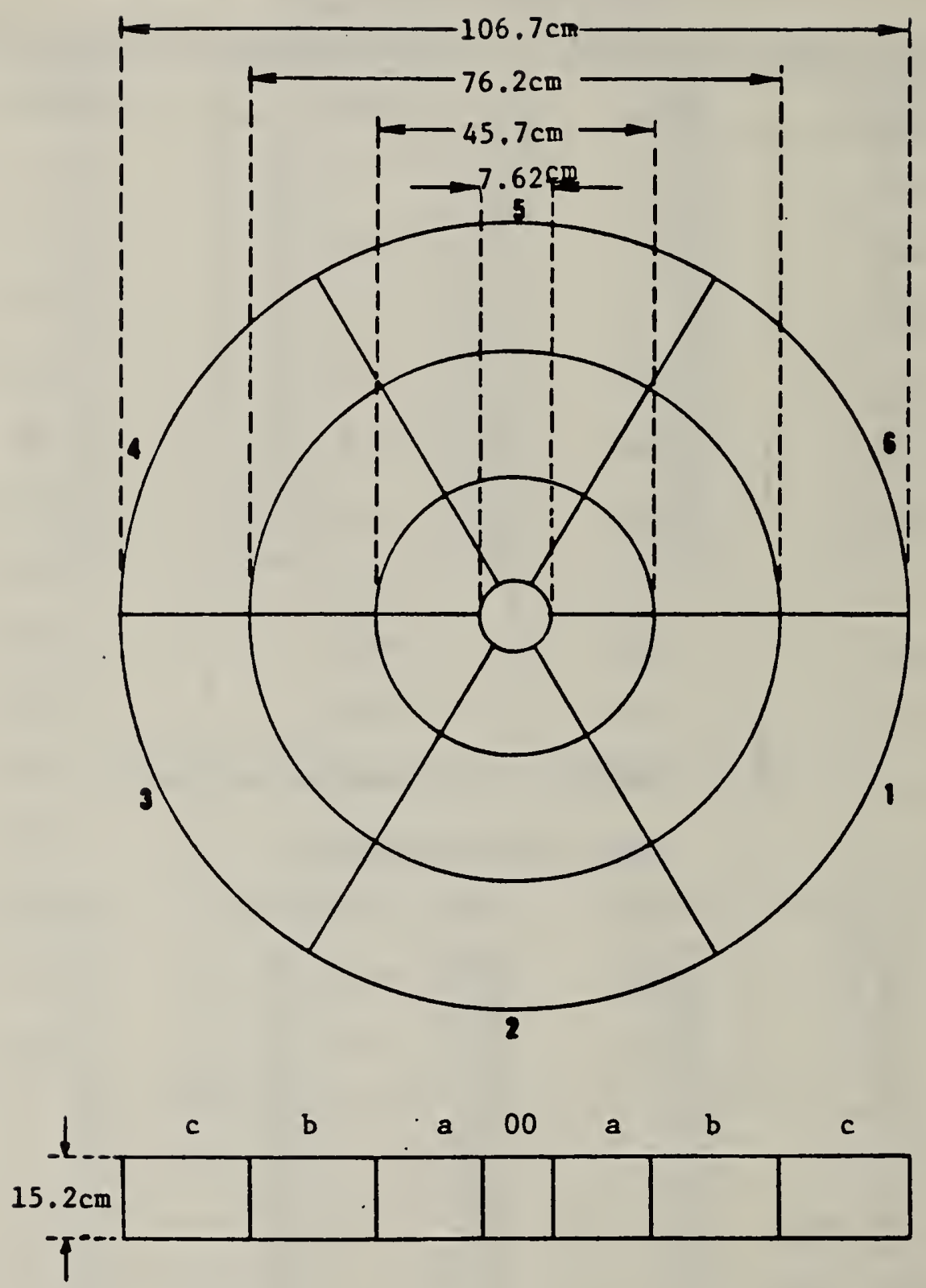

Figure 1. Water collection device - "sector rig" - geometry and dimensions 

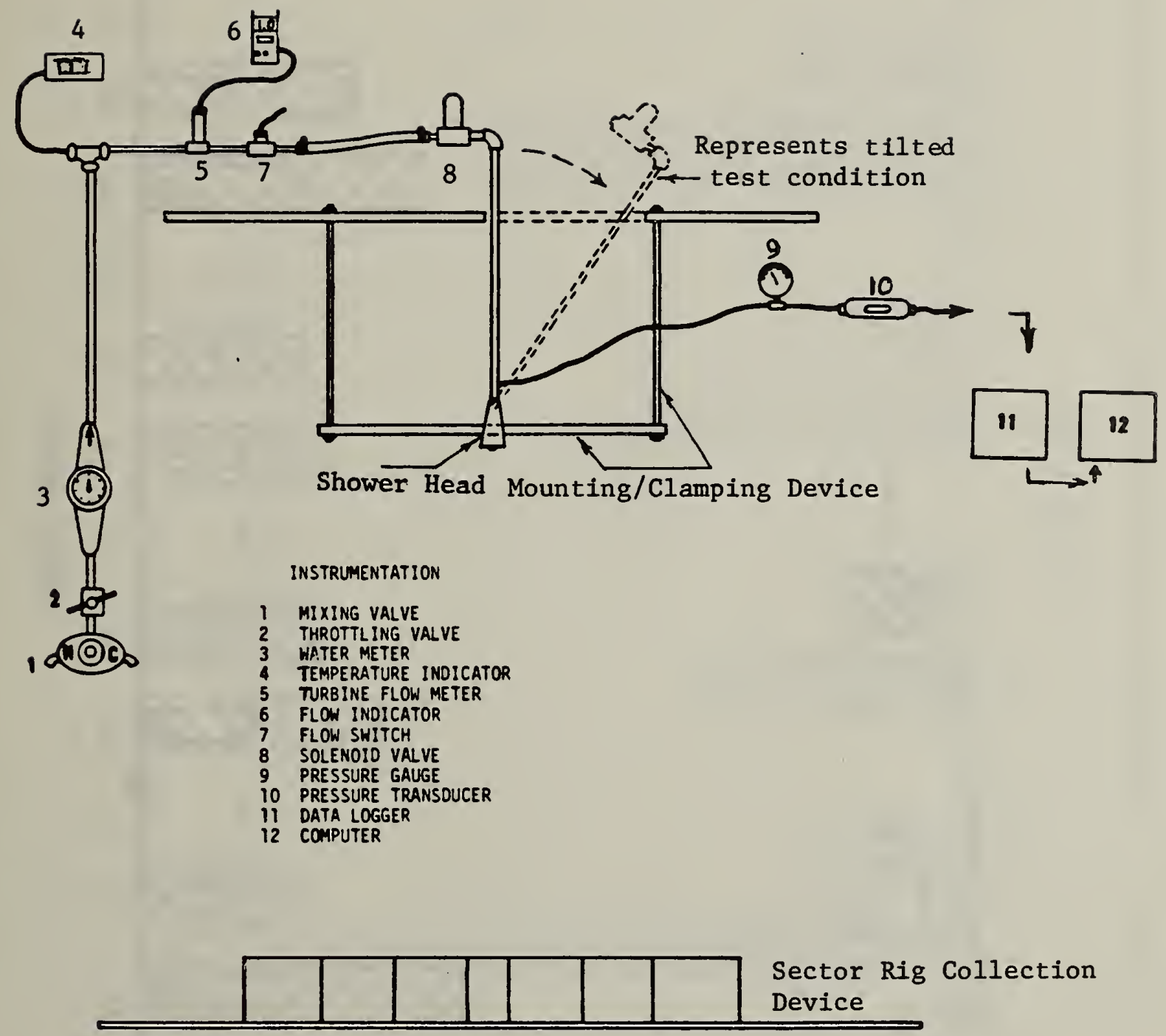

Figure 2. Shower head test configuration 


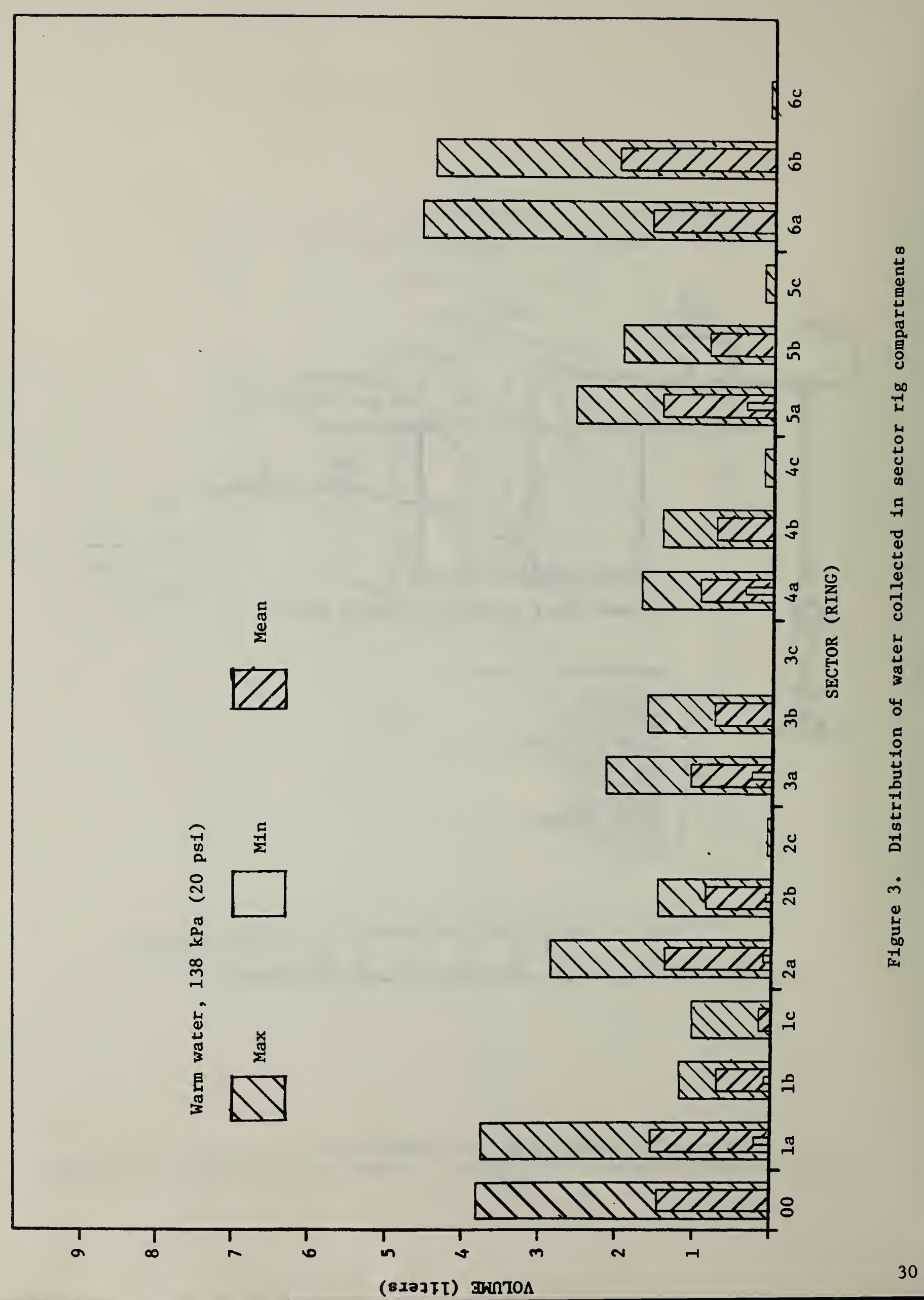




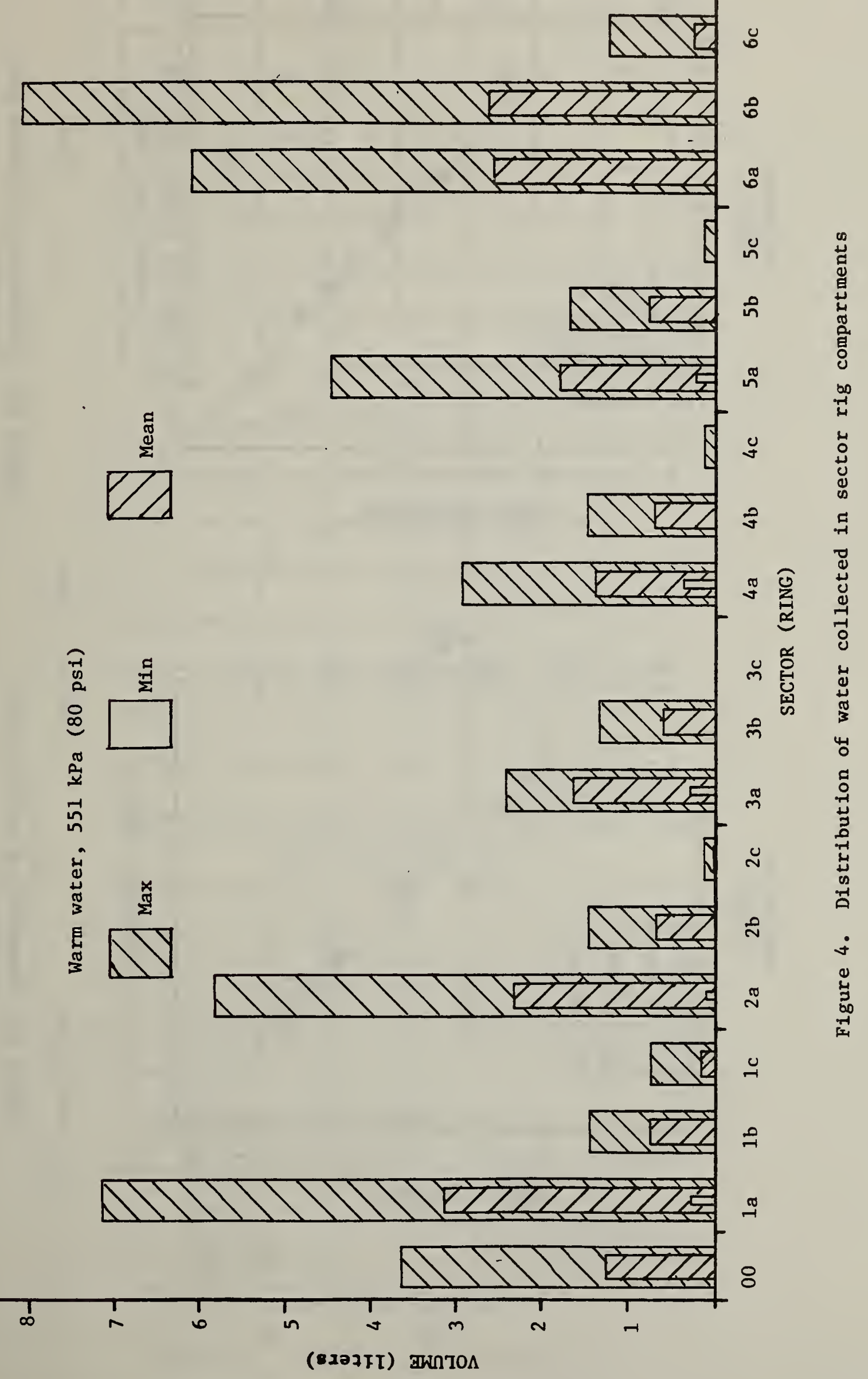




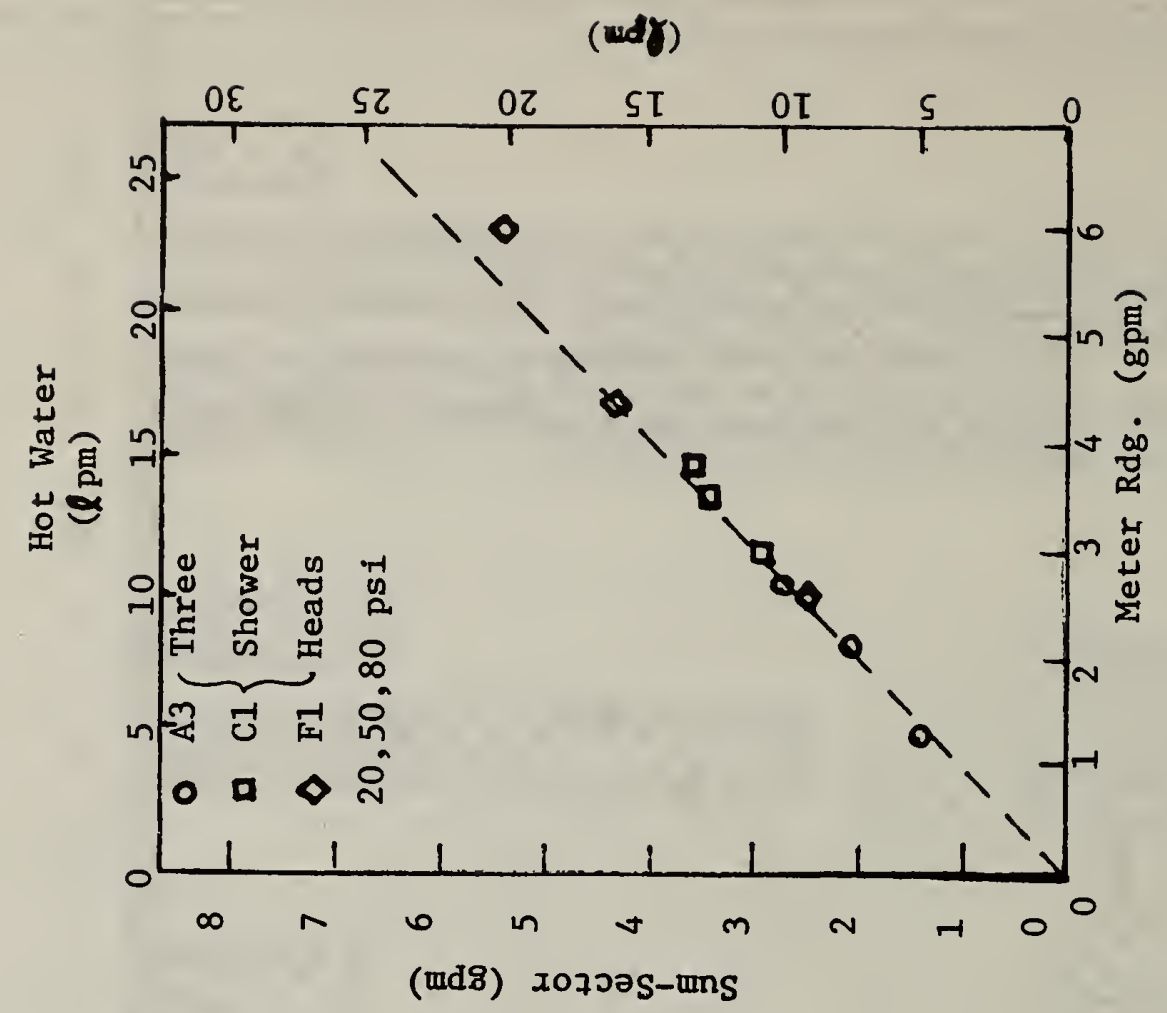

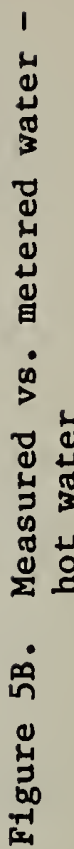

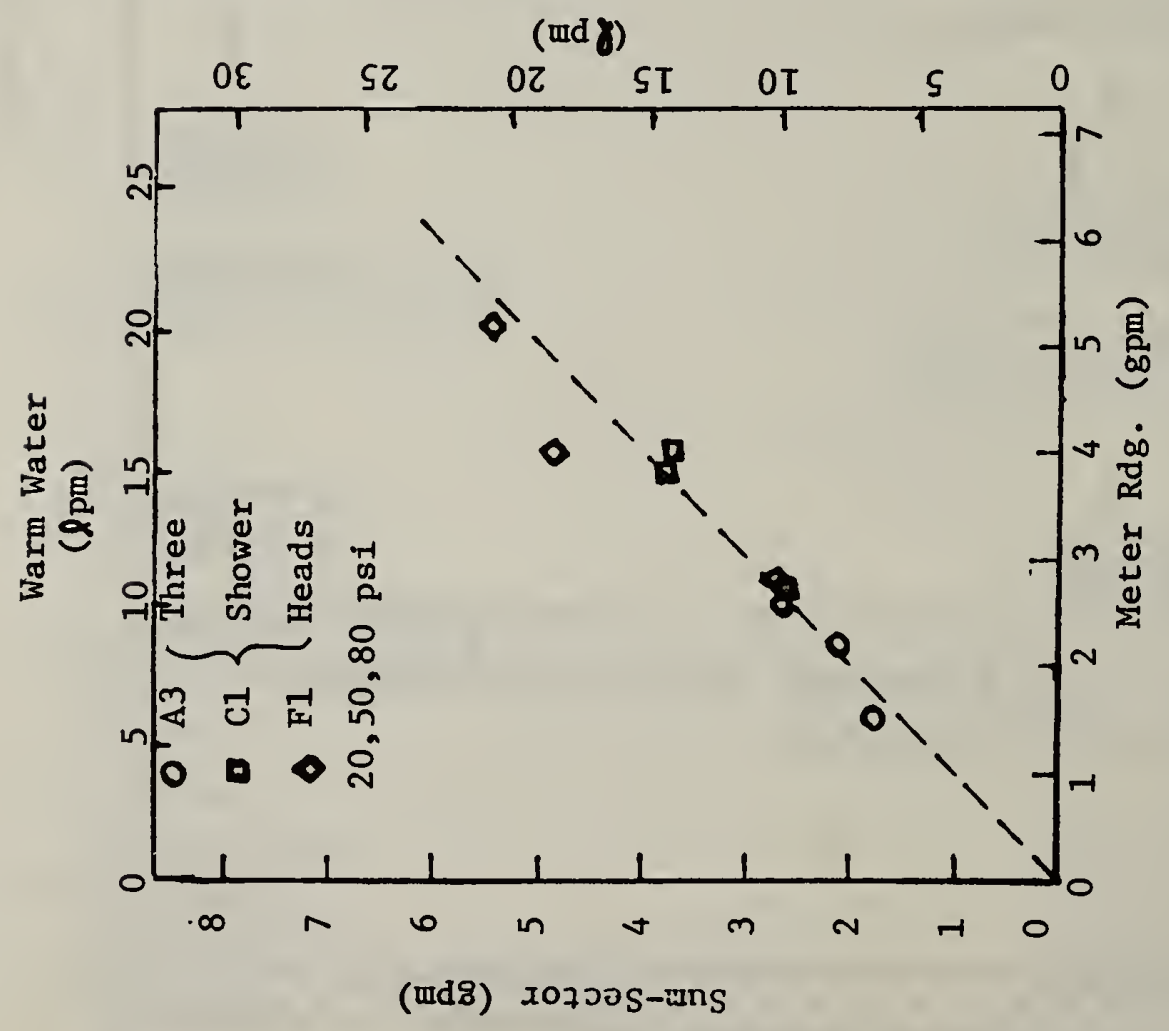

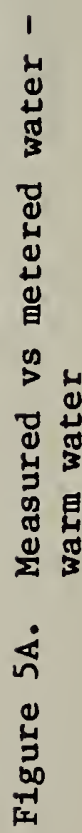


Snower Meod Test Rasulis
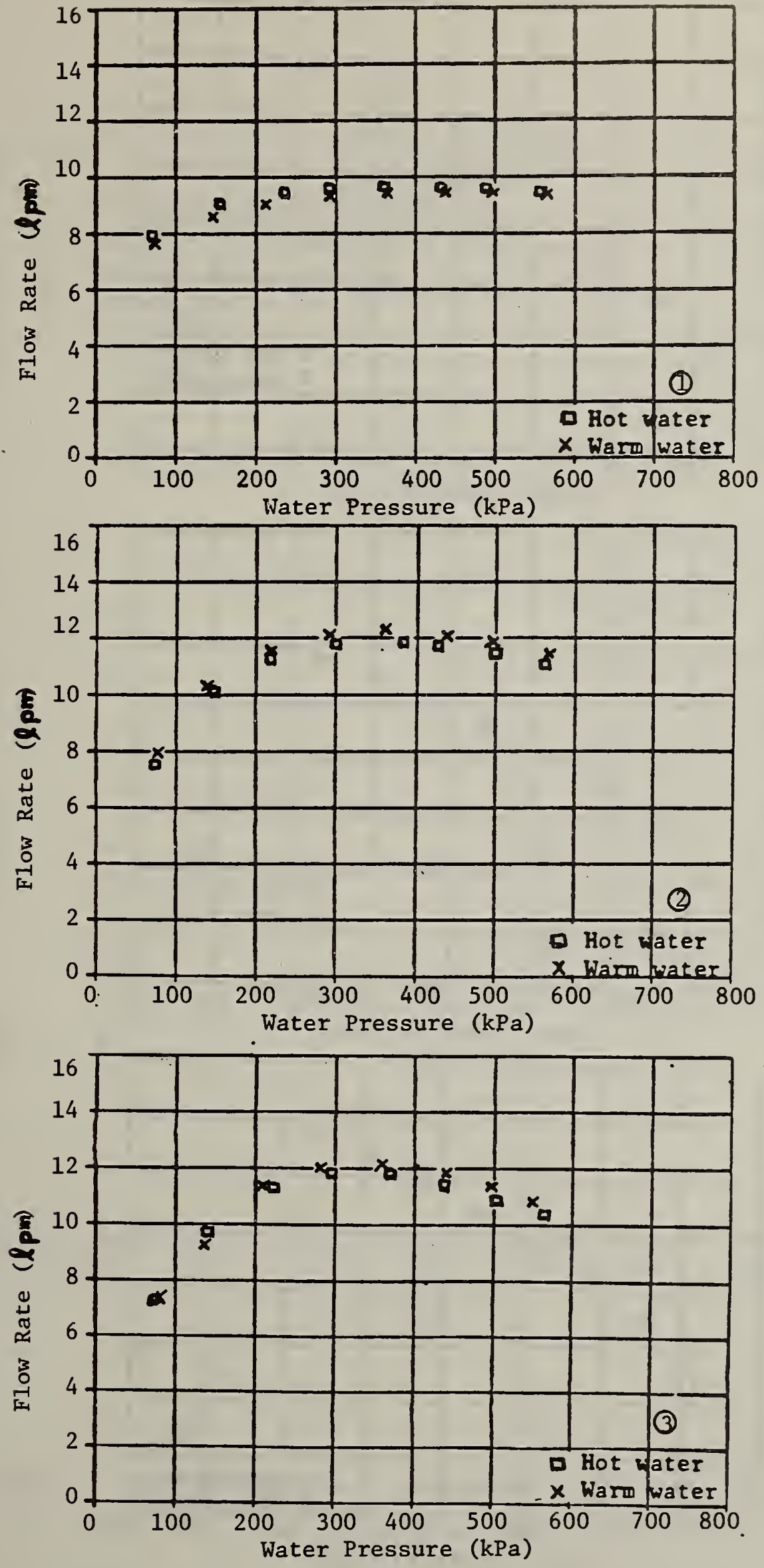

Figure 6A. Water flow rate vs pressure 
Snowar Heod test Resulto
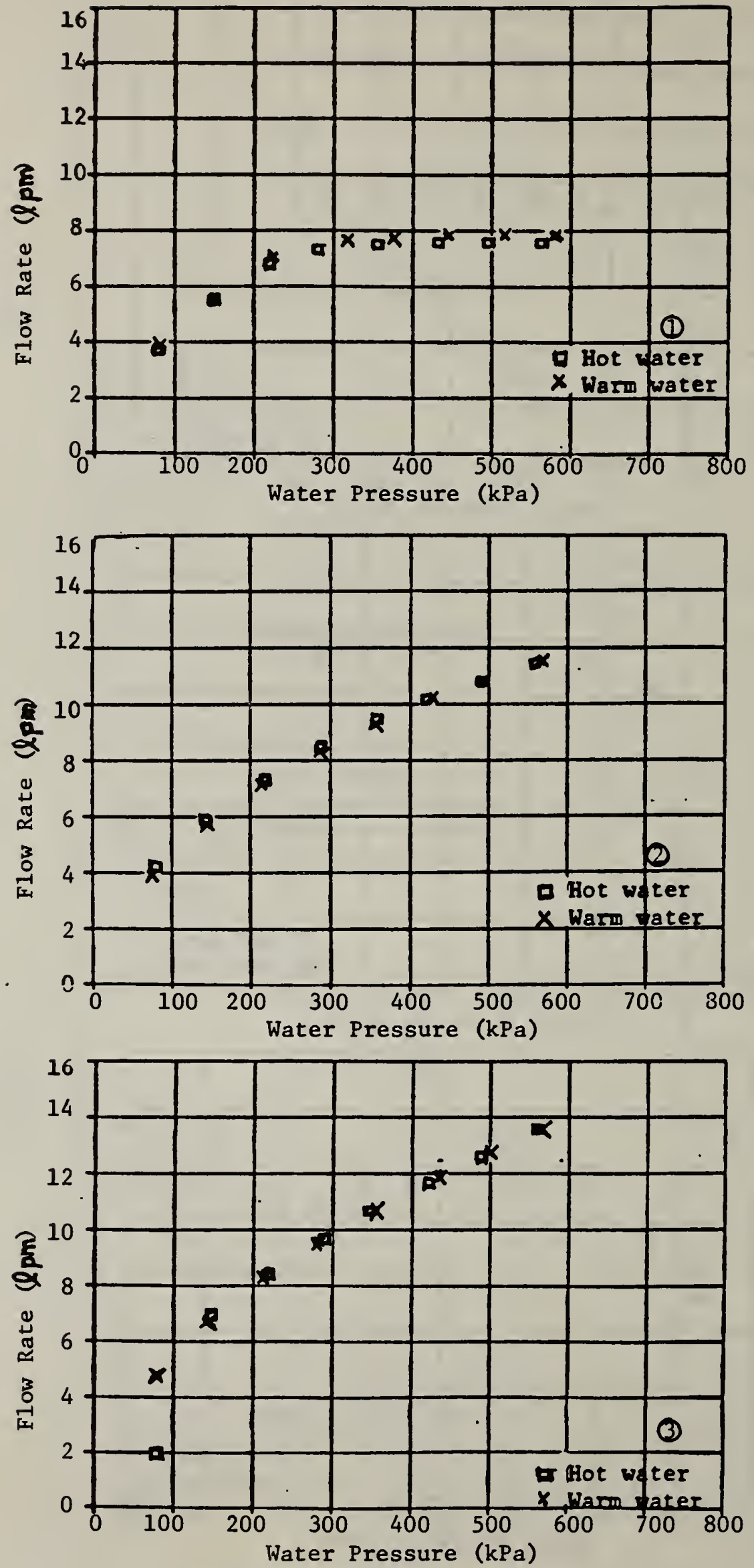

Figure $6 \mathrm{~B}$. Water flow rate vs pressure 


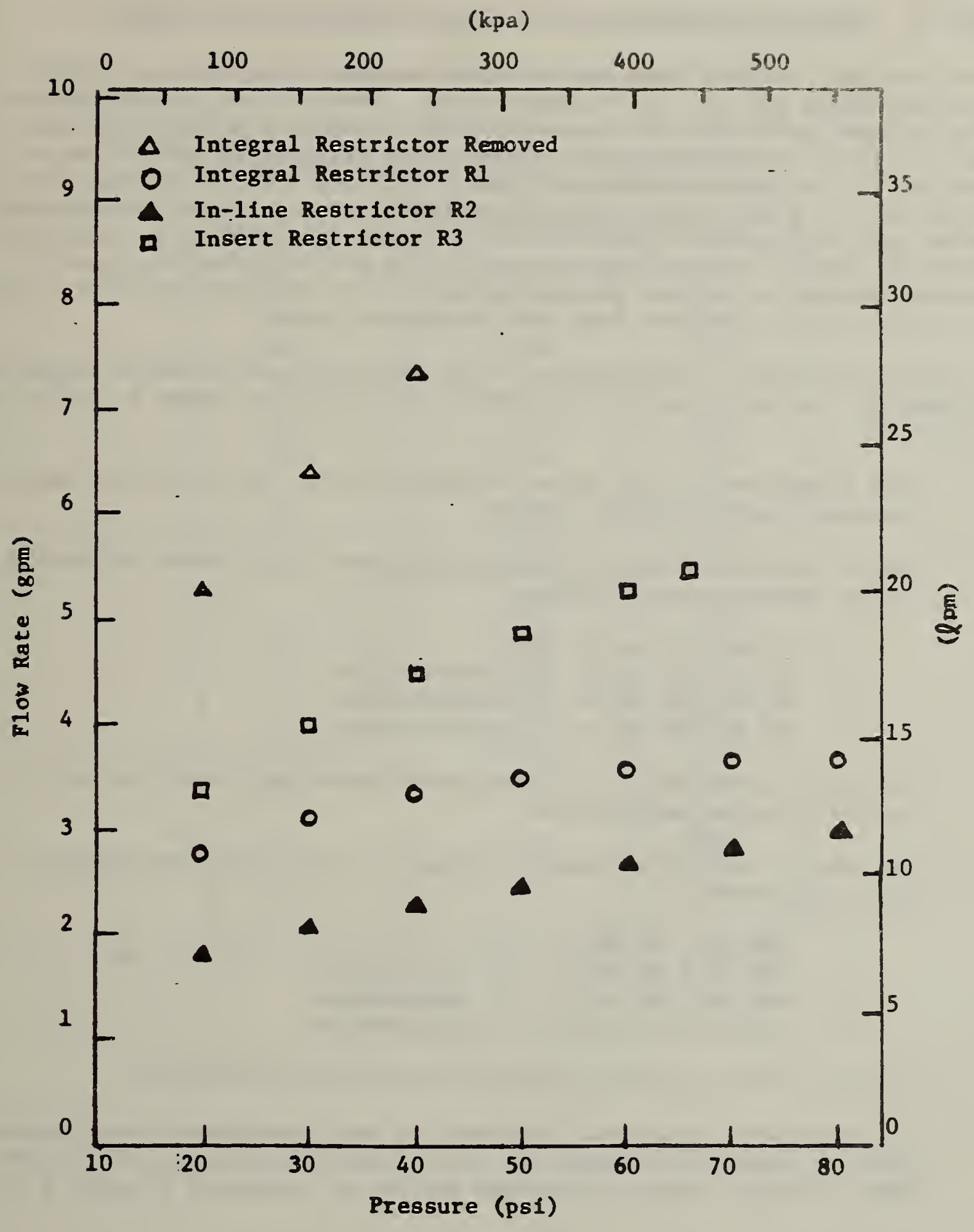

Figure 7. Water flow rate vs pressure - flow restrictors 
APPENDIX A. WATER COLLECTION DEVICE CALIBRATION PROCEDURE AND RESULTS

The raw test data obtained from the water collection device consist of water level measurements for each of 19 compartments. These values (in centimeters of water height) multiplied by the calibration constants provide the volumes of water in liters or gallons.* The constants or calibration factors may be theoretically calculated, assuming zero wall thickness, from an equation for volume based upon equal angular sectors and radial rings. Actual calibrations are based upon the procedure below for the as-built inaccuracies in the sector geometry and physical material thicknesses (table A-1 indicates very small differences between actual and assumed volumes). The calibration factors should not be significantly different from the theoretical values.

The calibration procedure (performed with the water collection device installed and leveled in the test location) is listed below (refer to figure 1 for the nomenclature):

a. Each compartment of the water collection device was drained of water completely and the holes plugged.

b. Initial volumes of measured water were added to the water collection device compartments as follows:*

$$
\begin{aligned}
& \text { 1. } 120 \mathrm{ml}(4 \mathrm{oz}) \text { to "00" } \\
& \text { 2. } 240 \mathrm{ml}(8 \mathrm{oz}) \text { to "a" compartments } \\
& \text { 3. } 480 \mathrm{ml}(16 \mathrm{oz}) \text { to " } \mathrm{b} \text { " compartments } \\
& \text { 4. } 600 \mathrm{ml}(20 \mathrm{oz}) \text { to " } \mathrm{c} \text { " compartments }
\end{aligned}
$$

c. The water levels for each of the compartments were read from the graduated scales and recorded.

d. Incremental amounts of measured volumes of water were then added to each compartment:*

$$
\begin{aligned}
& \text { 1. } 960 \mathrm{ml}(32 \mathrm{oz}) \text { to "00" } \\
& \text { 2. } 1920 \mathrm{ml}(64 \mathrm{oz}) \text { to "a" compartments } \\
& \text { 3. } 3840 \mathrm{ml}(128 \mathrm{oz}) \text { to "b" compartments } \\
& \text { 4. } \quad 3840 \mathrm{ml}(128 \mathrm{oz}) \text { to "c" compartments }
\end{aligned}
$$

e. The water level in each compartment was read and recorded.

f. The calibration constants (factors) for each compartment were computed from the difference between the water level measurements and the two known volumes. These calibration values are tabulated in table $\mathrm{A}-1$.

Any conveniently graduated cylinder(s) may be used. 
Table A-1. Water Collection Device Callbration Results

Total volumes in each sector (gallons)

\begin{tabular}{|c|c|c|}
\hline Compartment & \multicolumn{2}{|c|}{ Calibration Factor } \\
\hline & $\begin{array}{l}\text { Theoretical } \\
\text { (predicted) }\end{array}$ & $\begin{array}{c}\text { Actual } \\
\text { (measured) }\end{array}$ \\
\hline 00 & .0214 & .0219 \\
\hline $1 \mathrm{a}$ & .0644 & .0658 \\
\hline $1 \mathrm{~b}$ & .1235 & .1250 \\
\hline lc & .1864 & .1887 \\
\hline $2 a$ & .0644 & .0641 \\
\hline $2 b$ & .1235 & .1266 \\
\hline $2 c$ & .1864 & .1923 \\
\hline $3 a$ & .0644 & .0641 \\
\hline $3 b$ & .1235 & .1235 \\
\hline $3 c$ & .1864 & .1887 \\
\hline $4 a$ & .0644 & .0649 \\
\hline $4 b$ & .1235 & .1235 \\
\hline $4 c$ & .1864 & .1887 \\
\hline $5 a$ & .0644 & .0649 \\
\hline $5 b$ & .1235 & .1220 \\
\hline $5 c$ & .1864 & .1887 \\
\hline $6 a$ & .0644 & .0649 \\
\hline $6 b$ & .1235 & .1250 \\
\hline $6 c$ & .1864 & .1887 \\
\hline & & - \\
\hline
\end{tabular}


This section briefly describes alternatives for depth measurement methods in the water collection device. The techniques discussed here provide improved resolution and reduce time required to make the depth measurements. The method described earlier with small plastic scales, requires reading the level of the miniscus for individual depths, which is not exact and may be cumbersome. Figures $B-1$ and $B-2$ are schematic diagrams which illustrate two alternative test apparatus configurations for determining the sector water depth. These methods require either a manometer bank and or installed pressure transducers.

The test configuration shown in figure B-l shows a method to determine the depth of water collected in the test by substituting water manometers in place of the graduated scales. In this arrangement each compartment of the water collection device would have the water depth measured by attaching a pressure tap to a tube connected to a graduated and calibrated vertical or inclined manometer. The depth of the water in the compartment would be observed on the manometer and indicates the level of water in the corresponding sector. For the configuration adopted in these tests, a bank of 19 manometers would be required to completely determine the water levels of all the compartments of the water collection device. Additional fittings and components, such as a solenoid or manual valve and tee connection to facilitate draining of the collector device would be installed at each pressure tap or bottom of the compartment. Residual water in a compartment could be accommodated by recording the initial and final values and the difference represents the collected water. The manometer bank would simplify recording of the water depth measurements and eliminate the awkward and tedious data gathering procedure inherent in the method utilizing the graduated scales. The addition of a calibration conversion scale would indicate the volume directly and save another computational step.

The schematic of the apparatus illustrated in figure B-2 is similar to the instrumentation outlined in the above description of figure $B-1$. Here, however, the difference is the substitution of pressure transducers for the manometers. This technique requires costly transducers and signal conditioning equipment, which may be difficult to install and use, but provides a means of accurately automating the data collection to acquire data rapidly and efficiently. For extended series of tests this method may be cost-effective since it completely eliminates the need to read the sector water levels manually. 


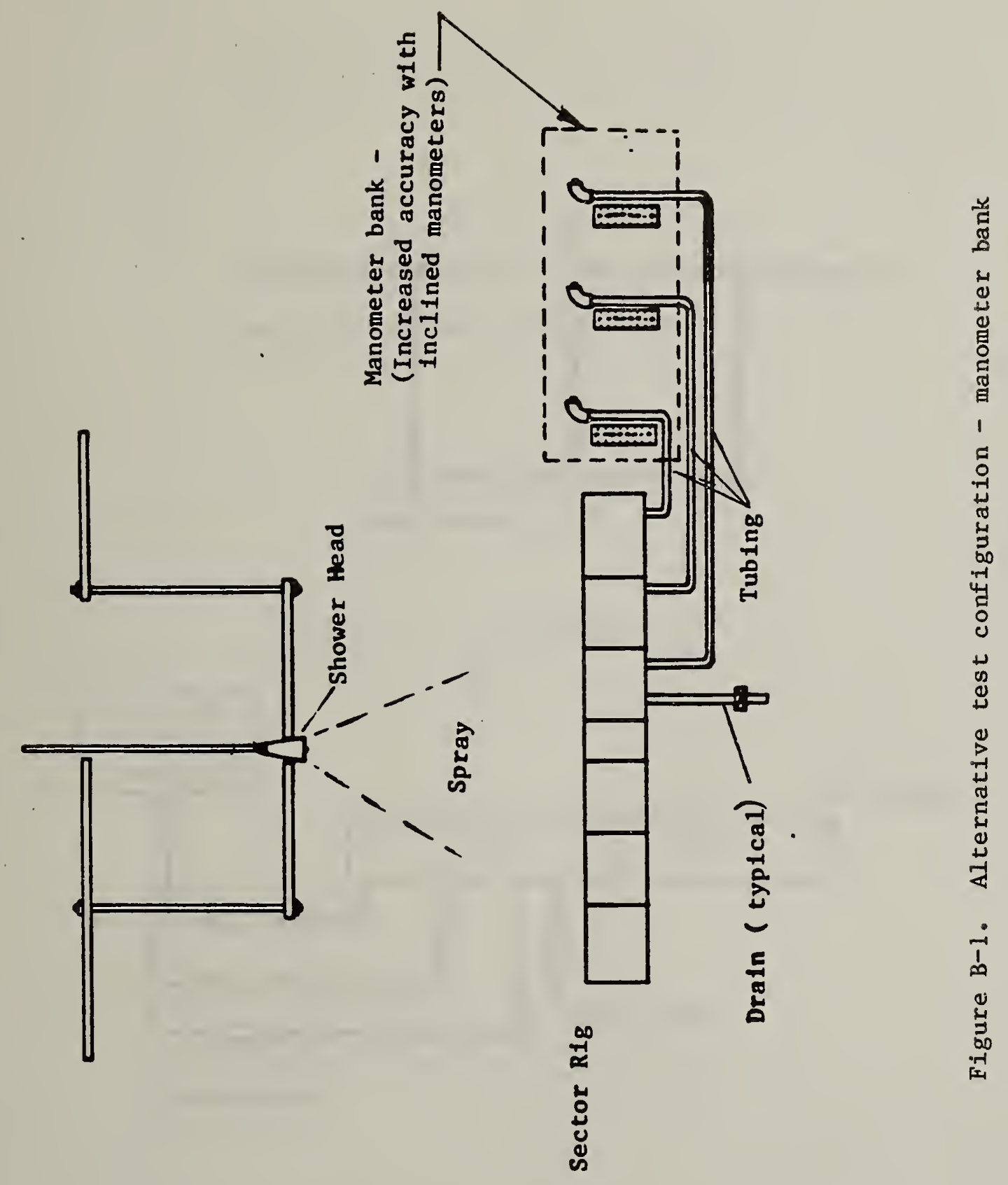



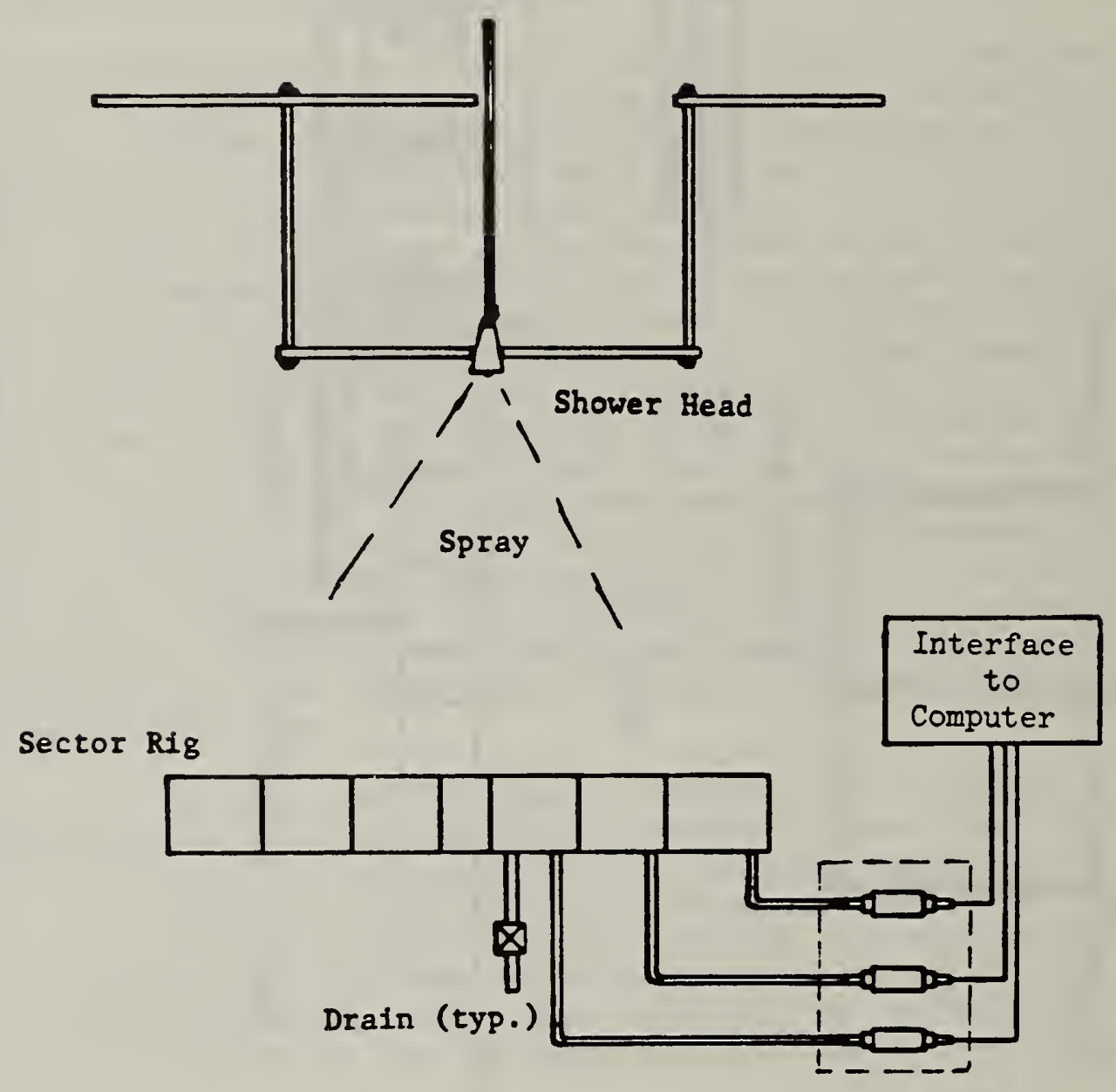

Transducers

Figure B-2. Alternative test configuration - pressure transducer bank. 
APPENDIX C

WATER COLLECTION DISTRIBUTIONS 

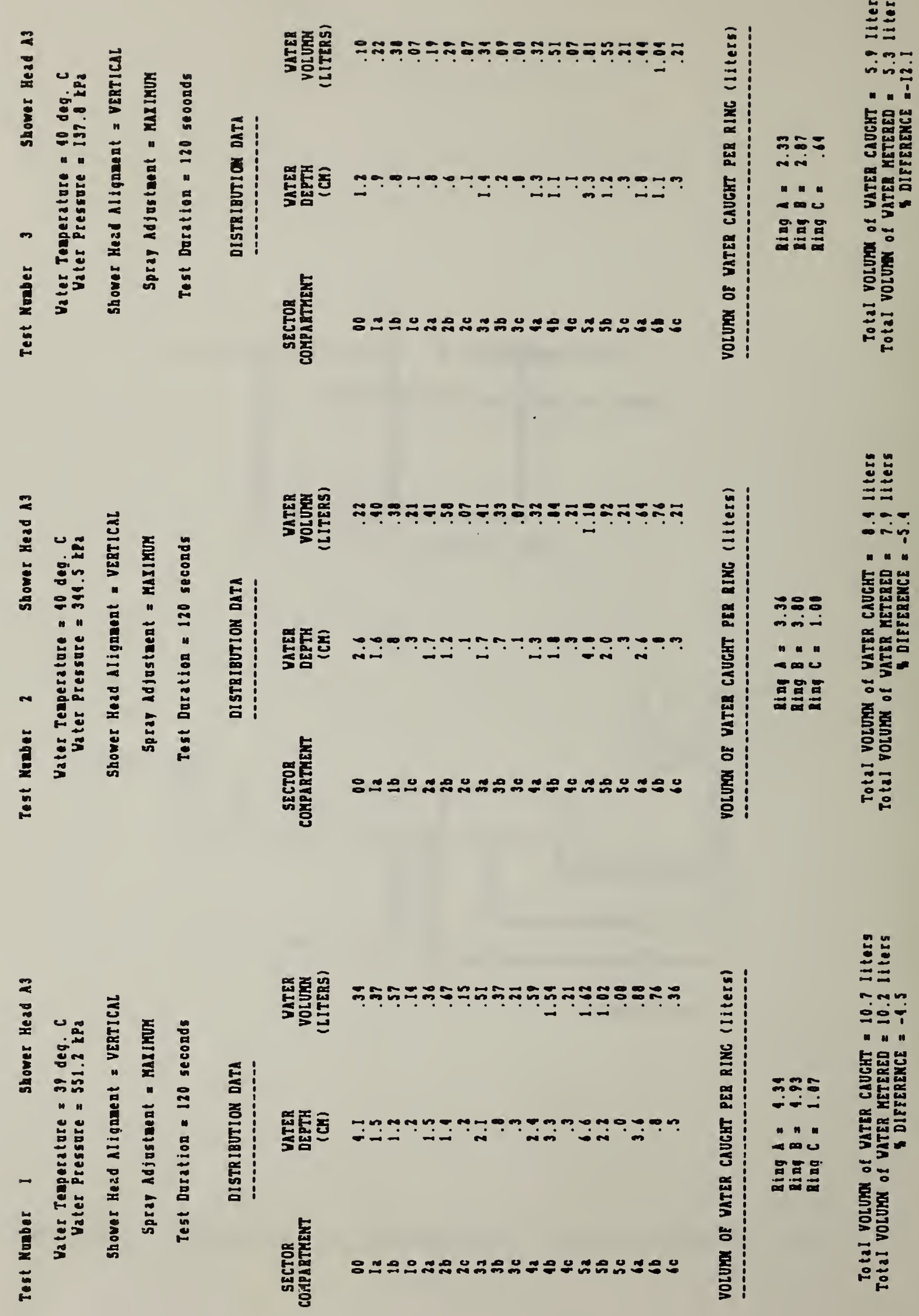

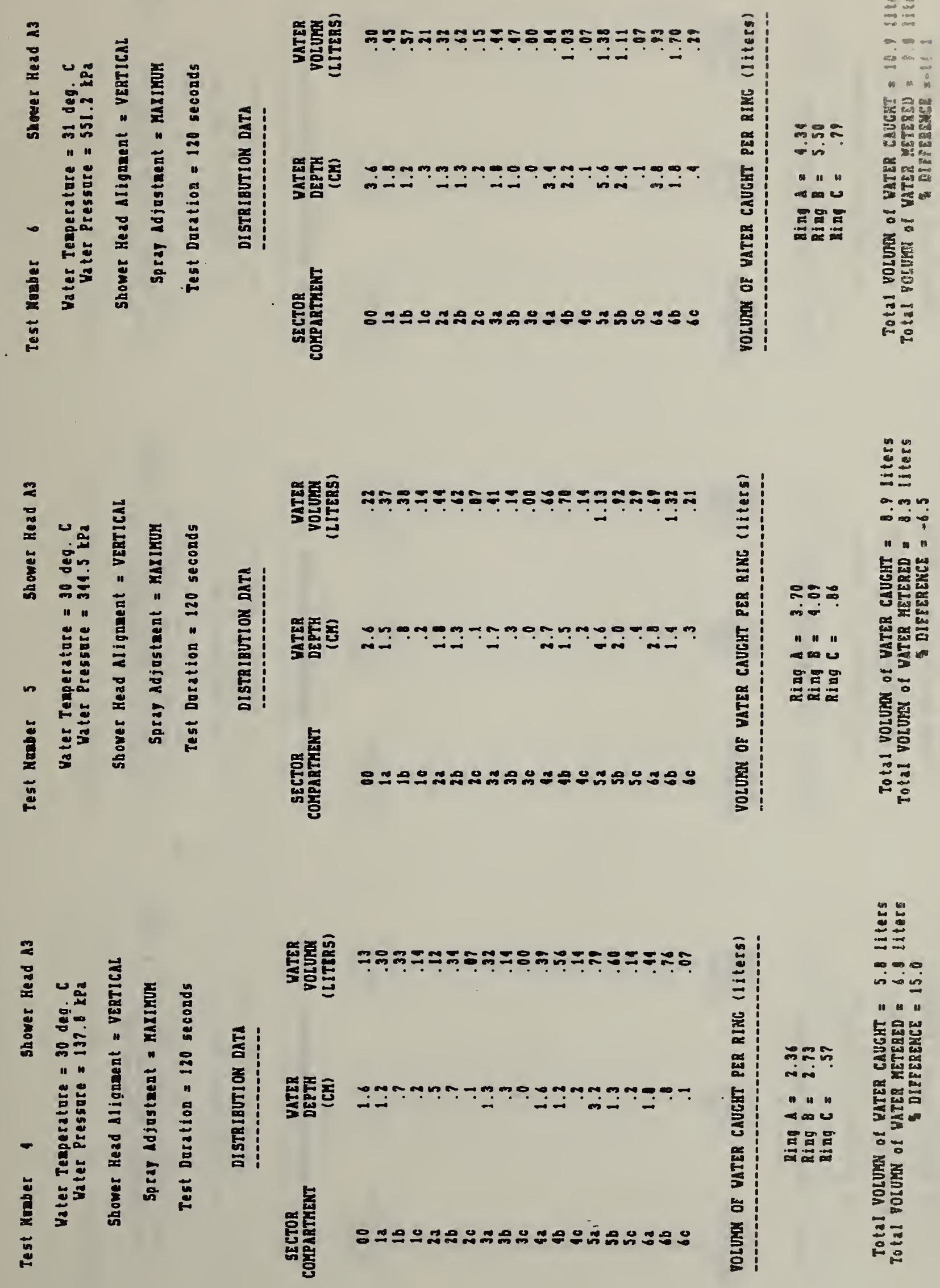

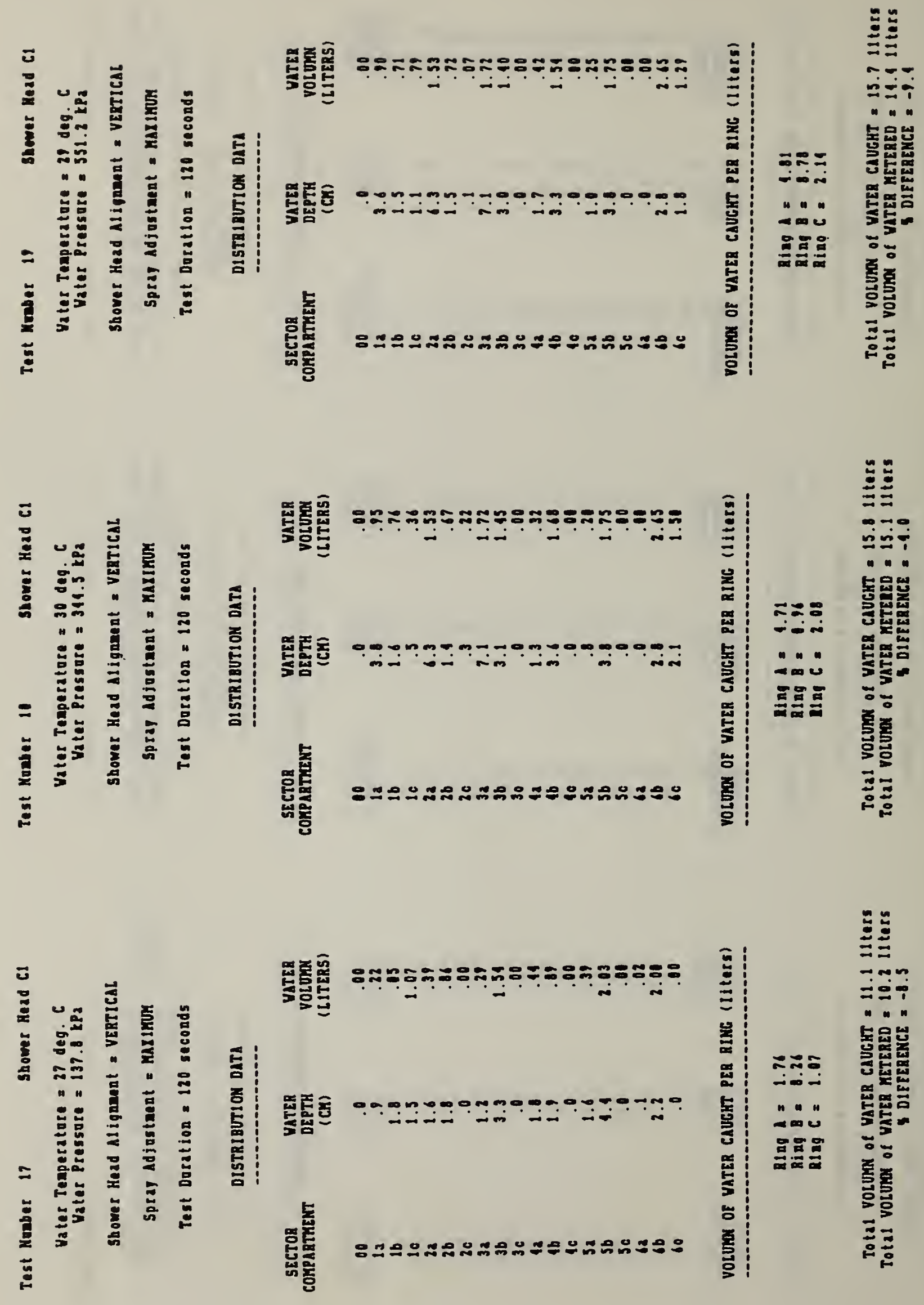

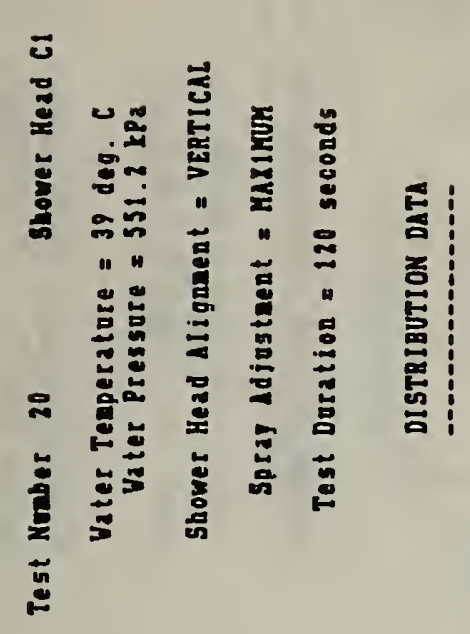

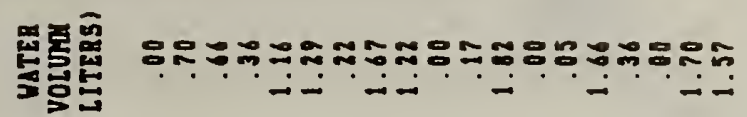

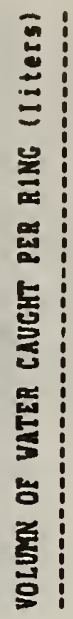

$\stackrel{g}{\Xi}$

$\rightarrow-\infty$

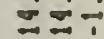

홈

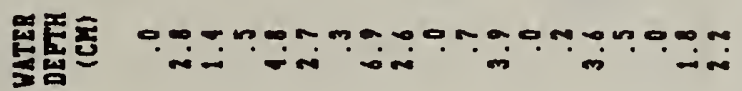

풍

"

in

일

슬

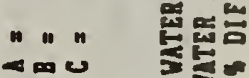

욤뭉

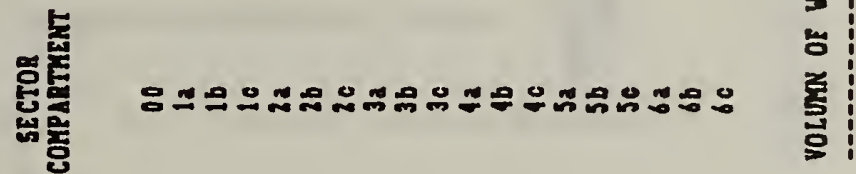

홍홍

总芯
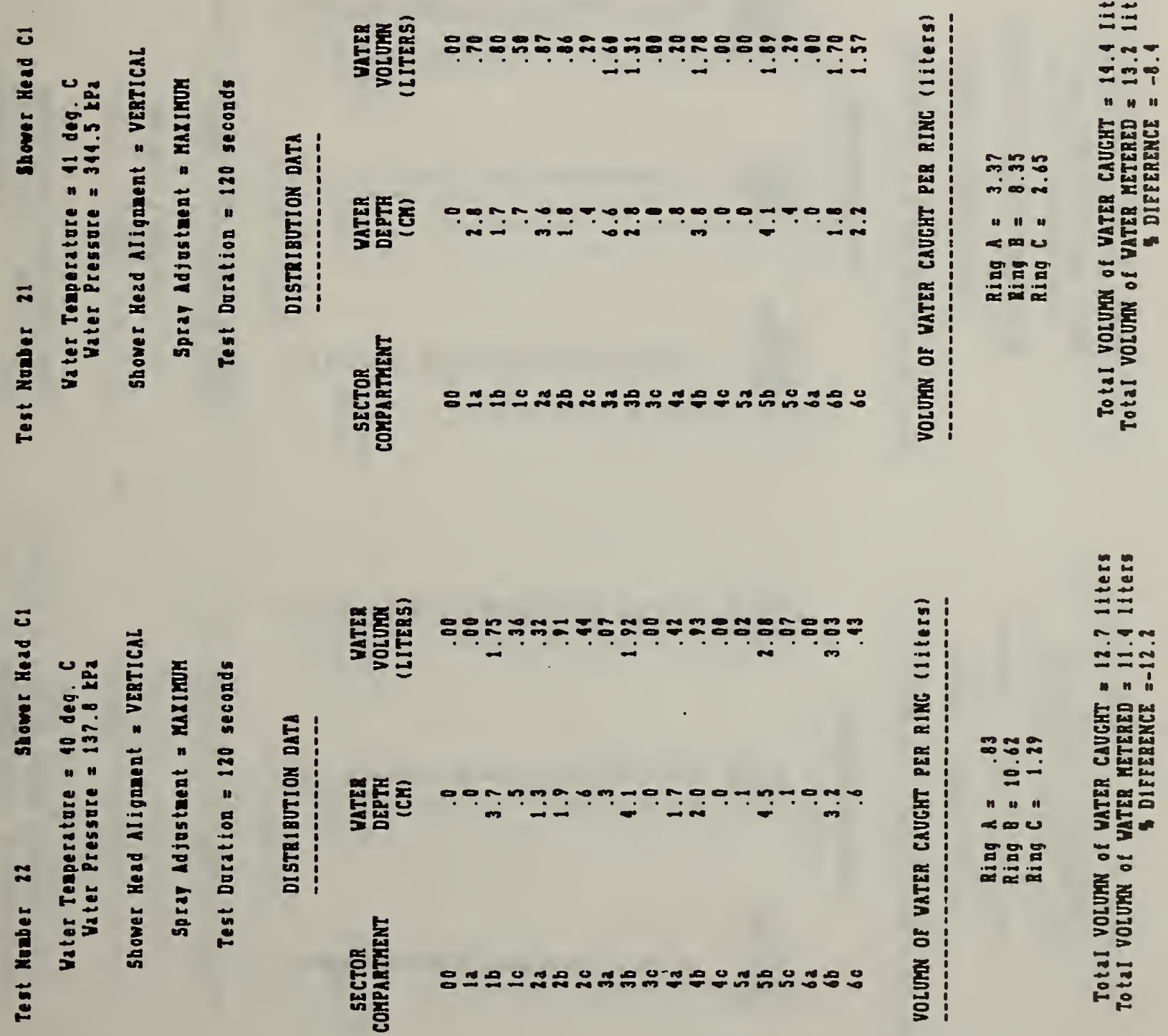

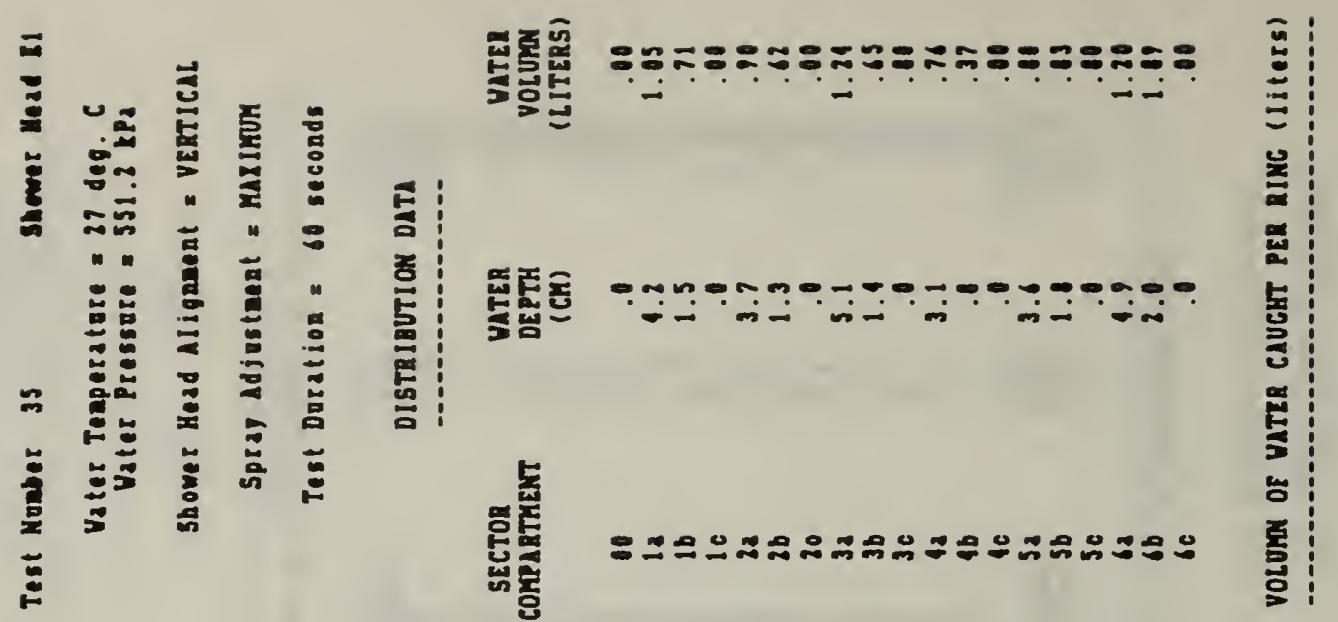

E
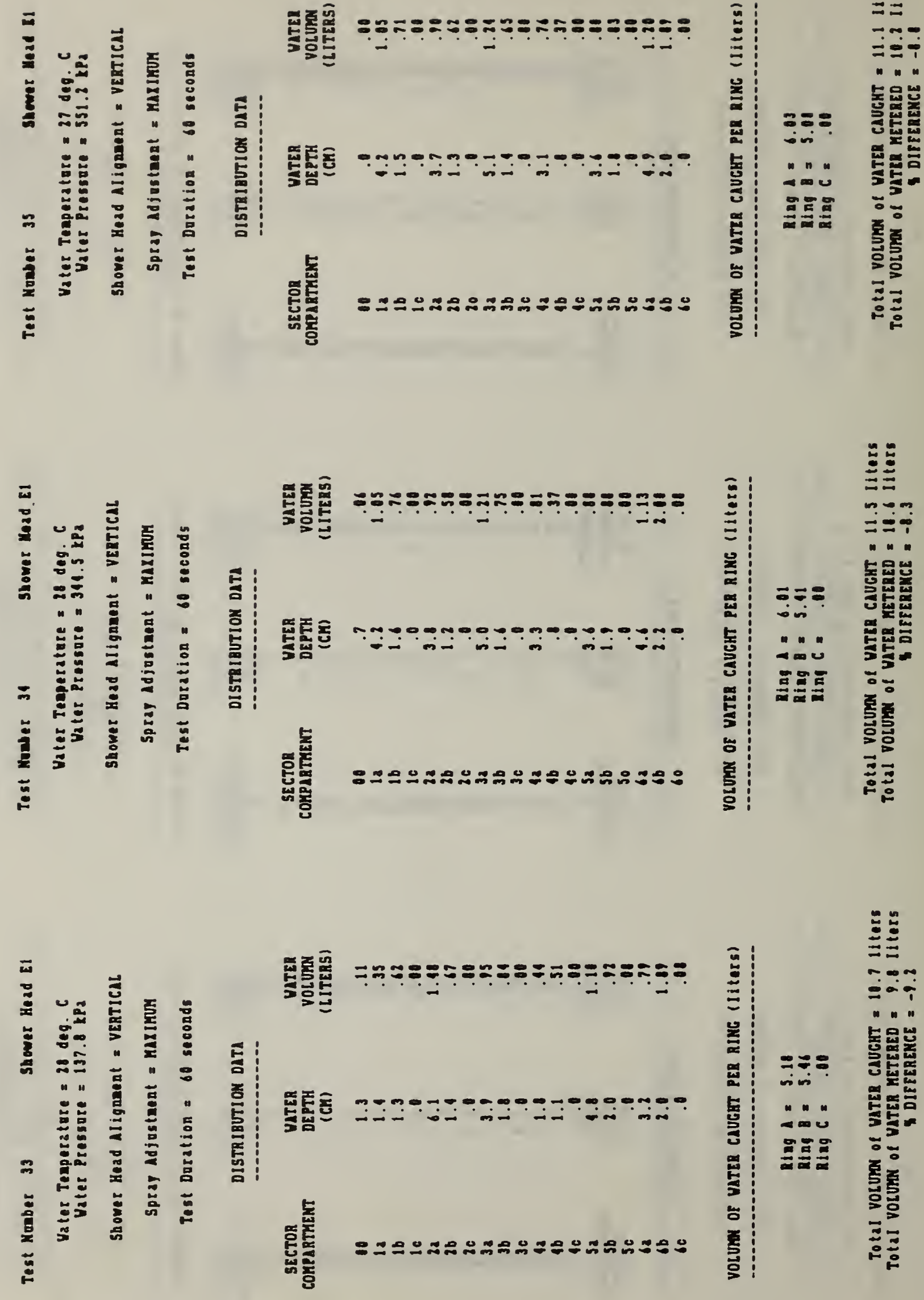

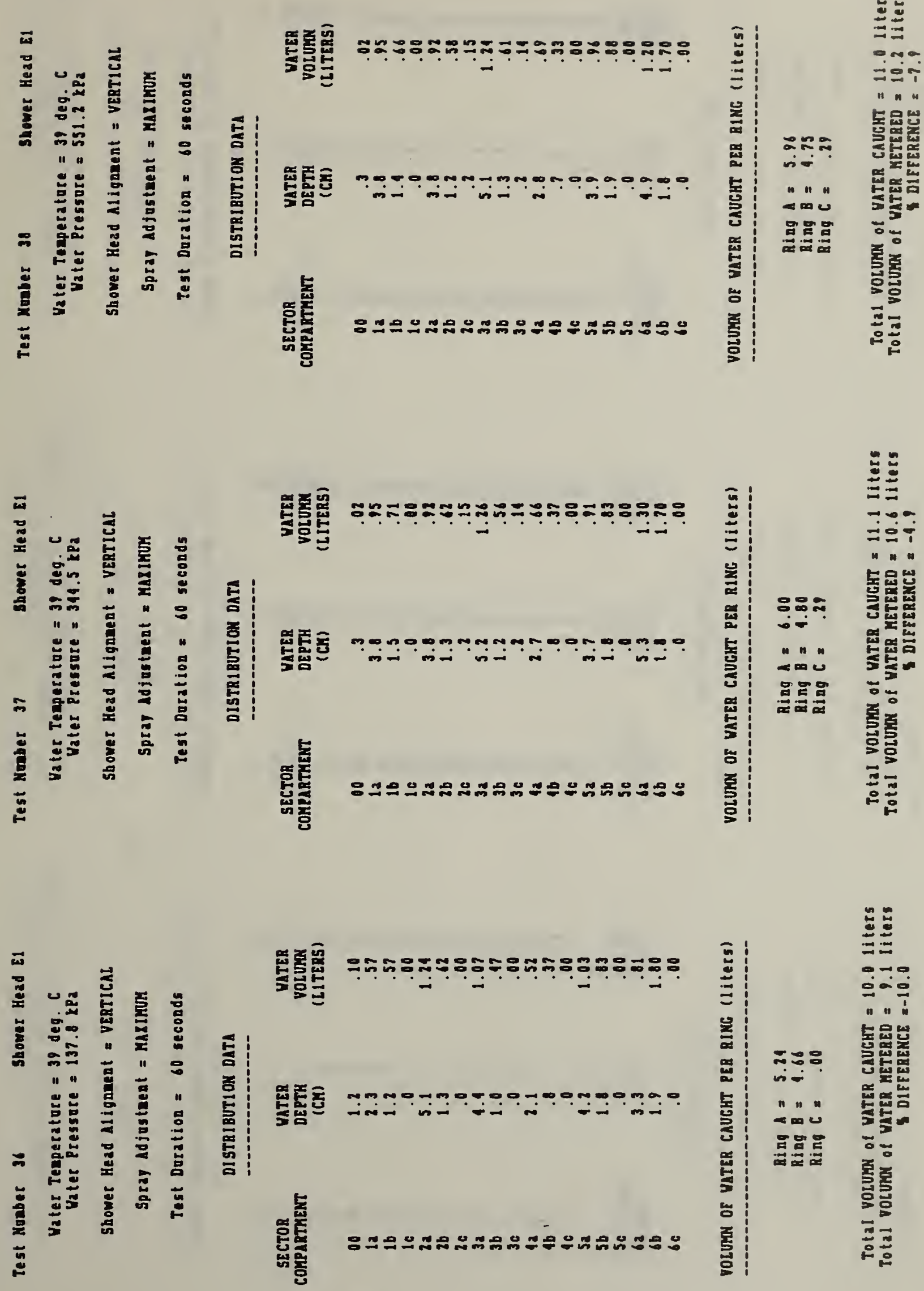

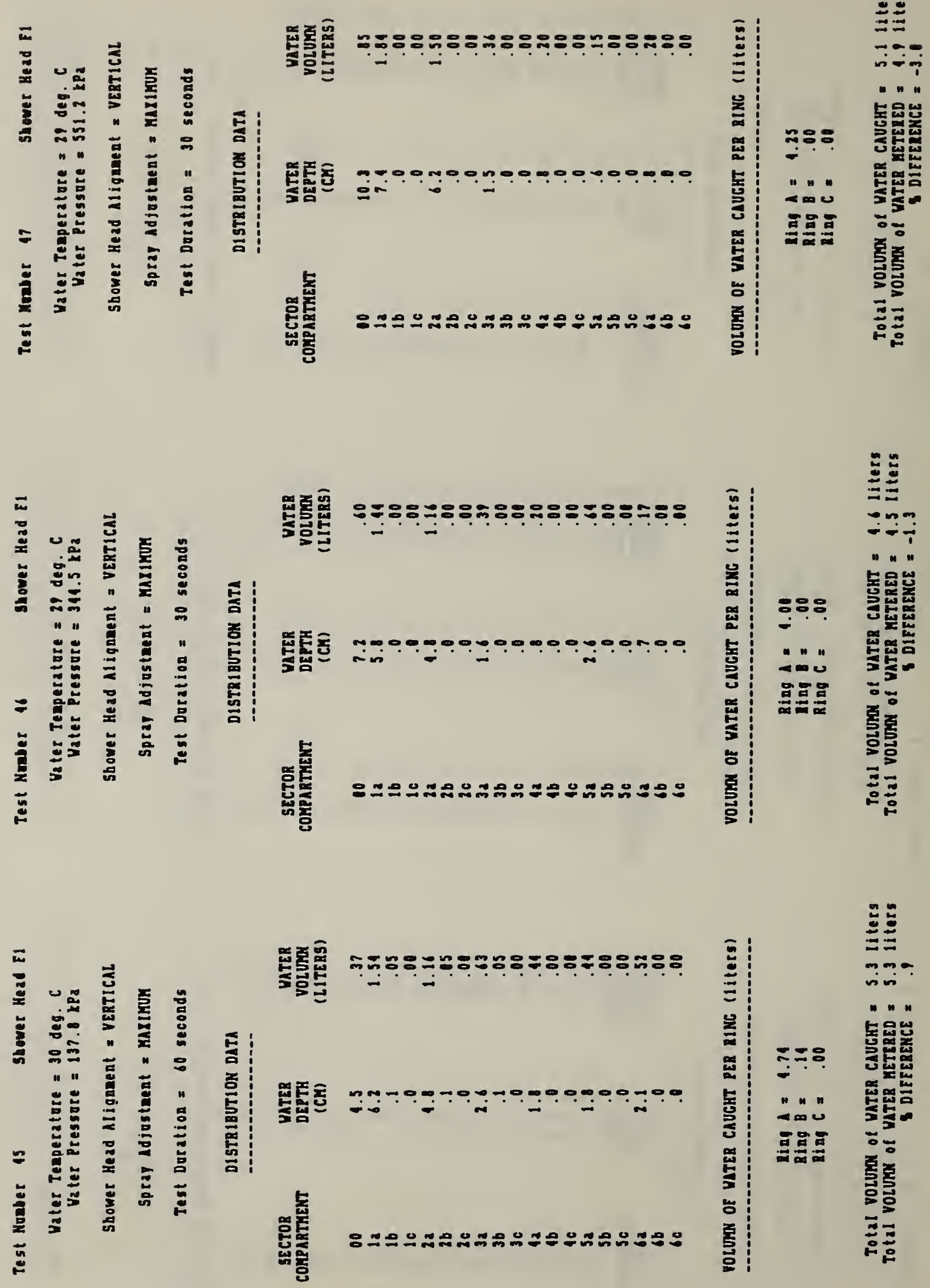

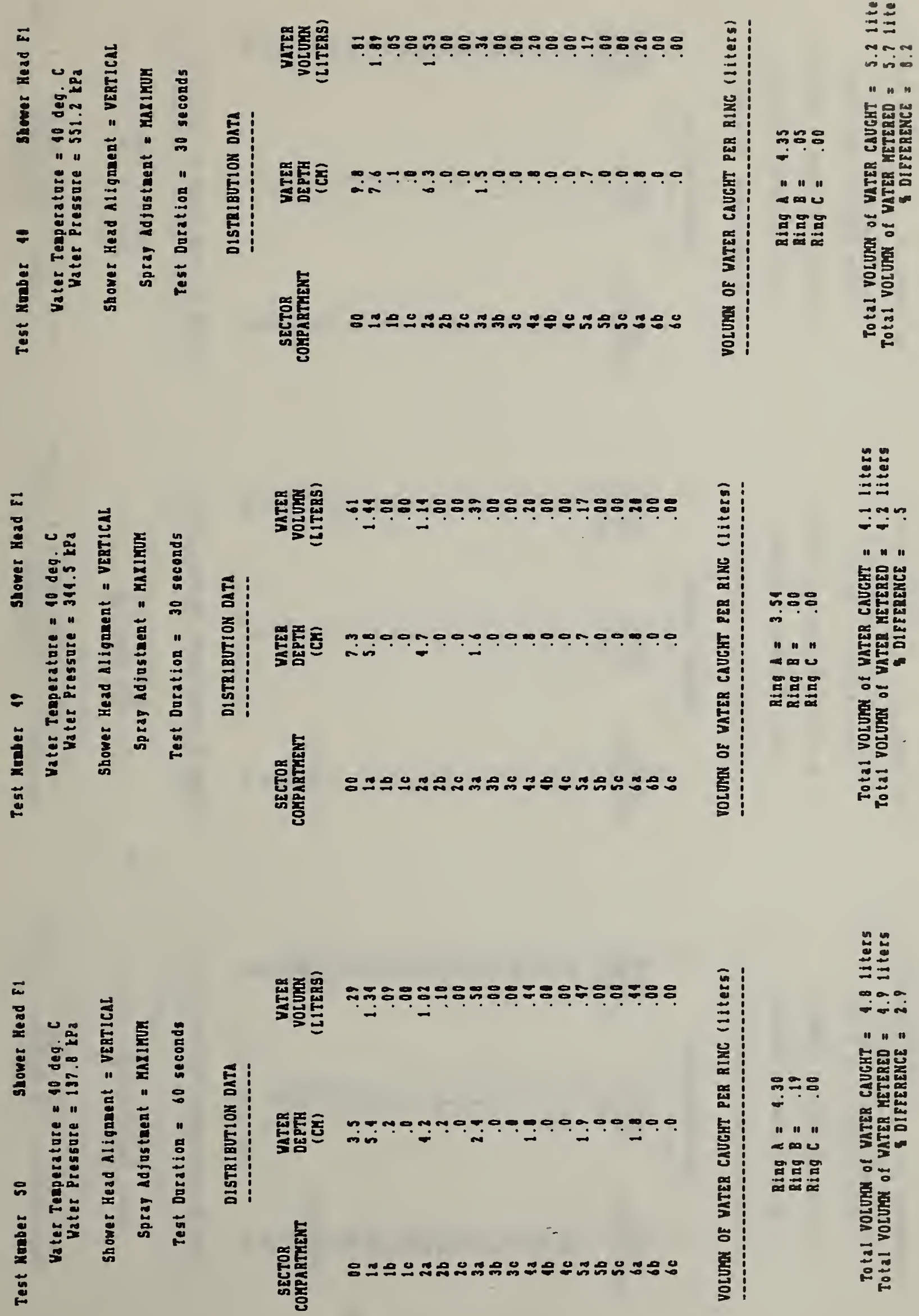

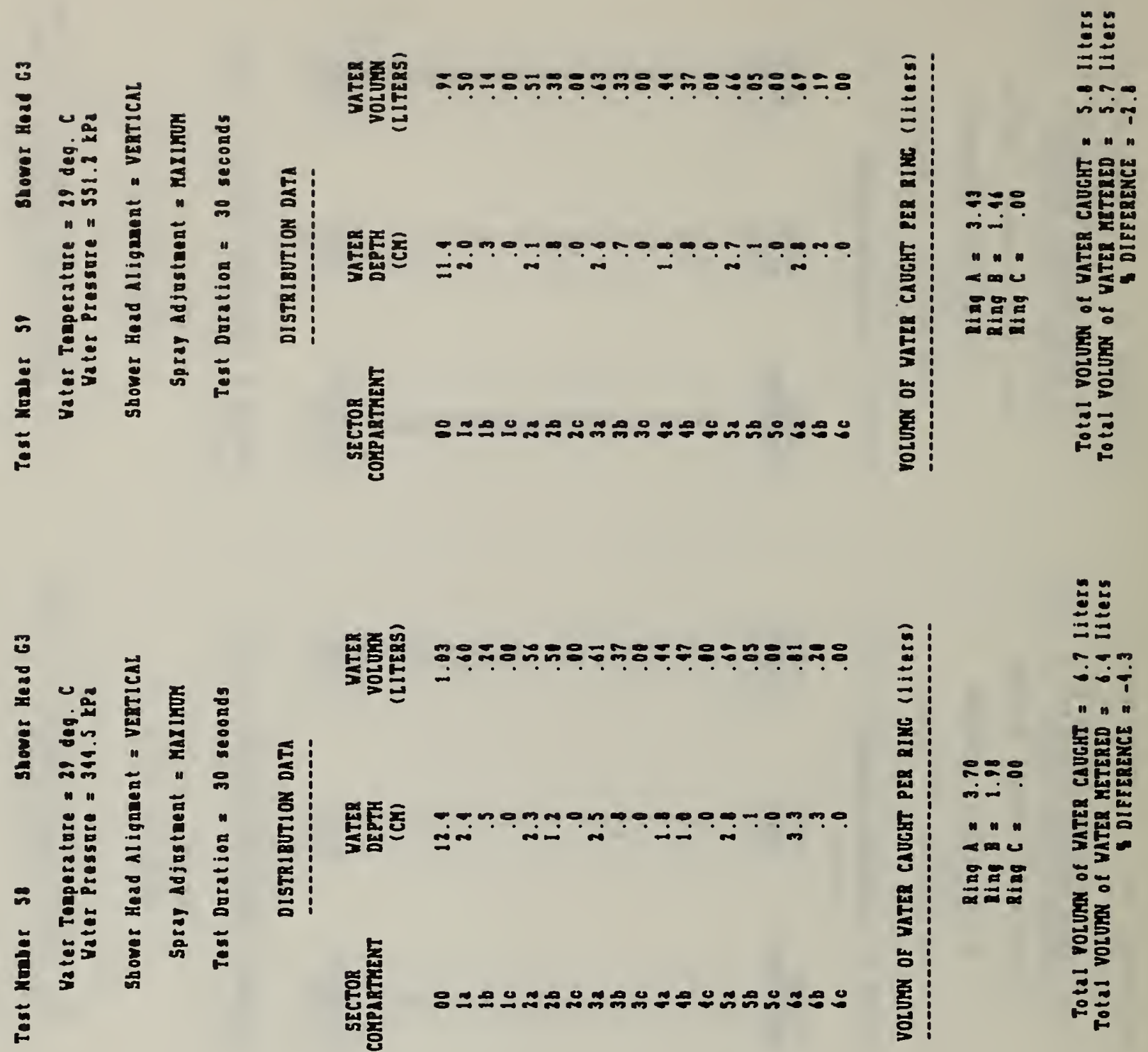

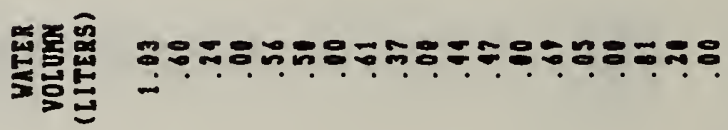

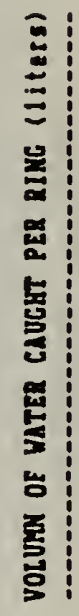

㱐
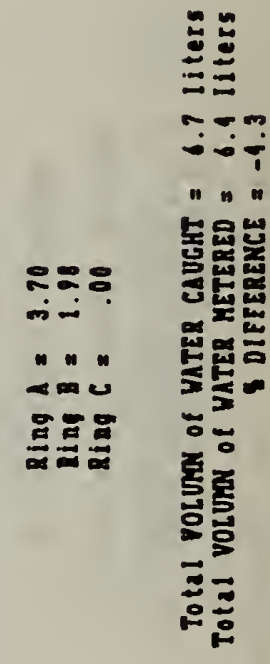

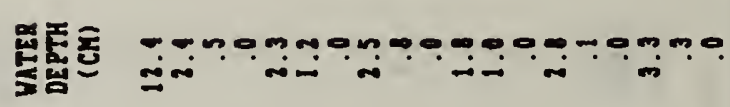

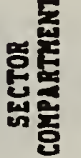

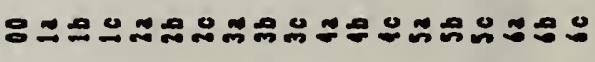
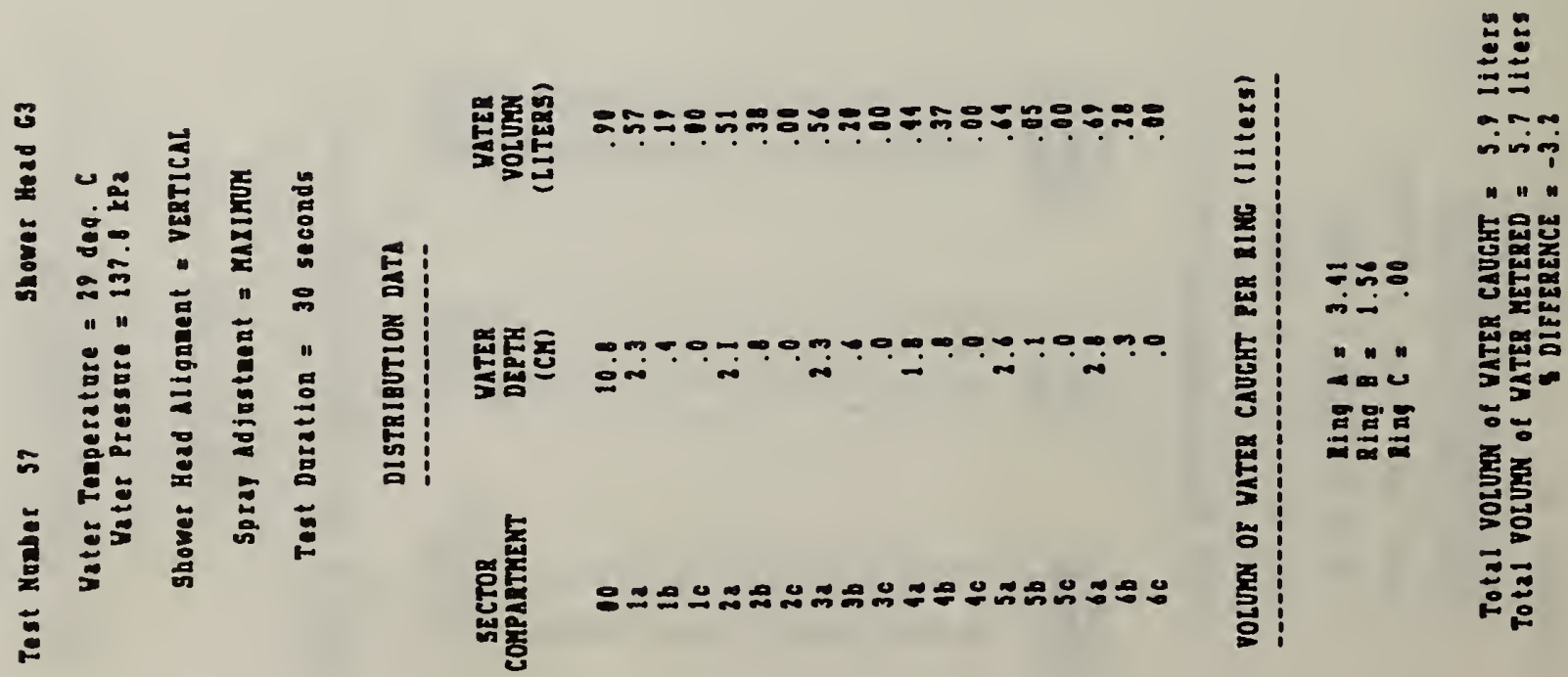

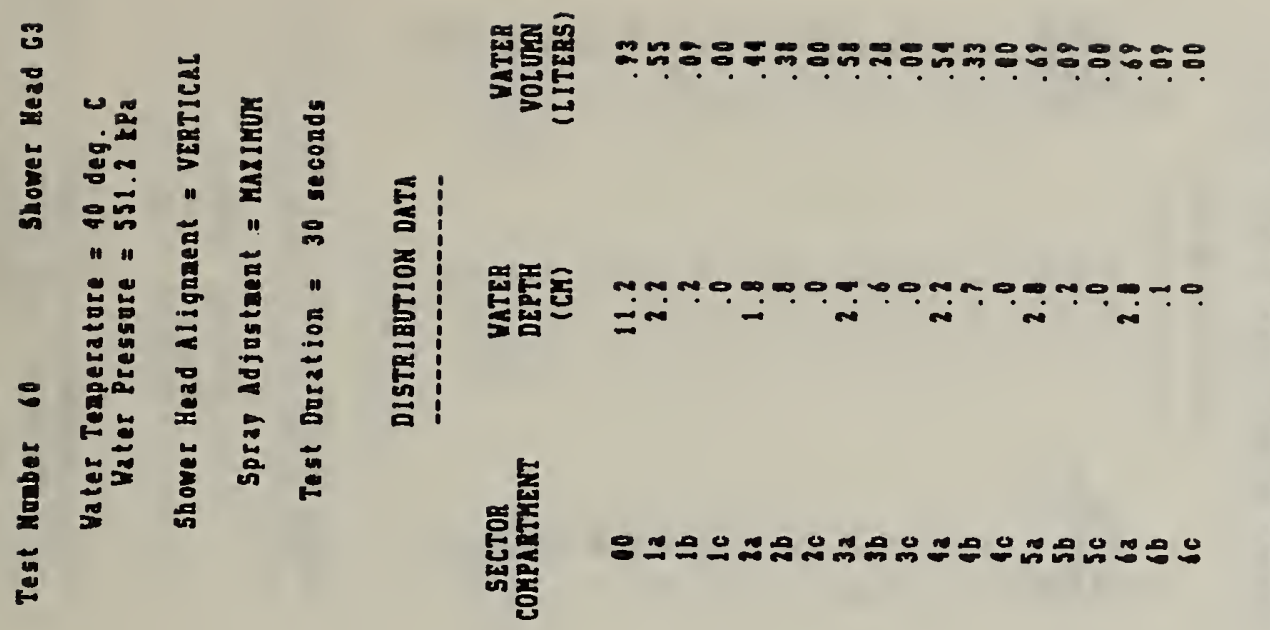

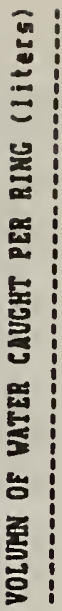

釆

$\div \approx=$

$m-$

n. "

$-\infty u$

압몀몸

$\because \div$

용

농면

可茲总

준

娄

镸

$\because=$
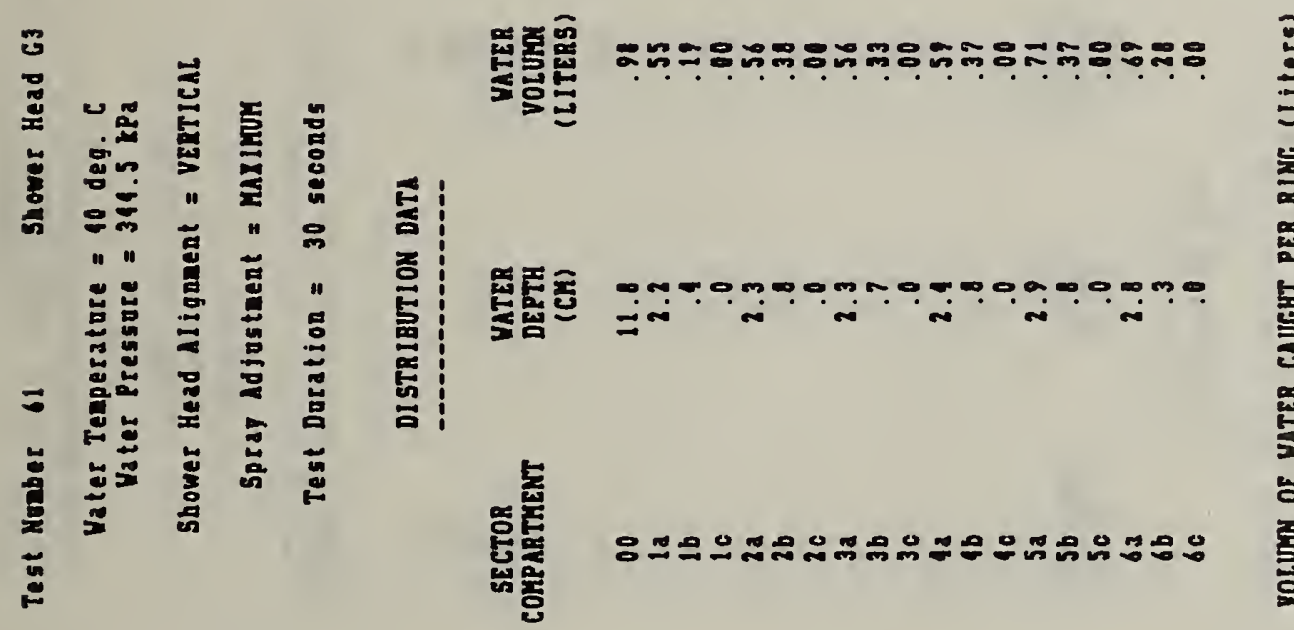

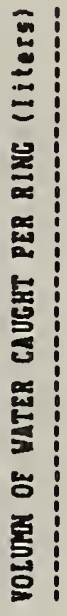

量竞

$\because \div \div$

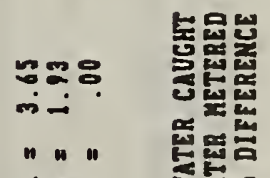

일

$=$

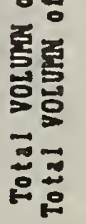
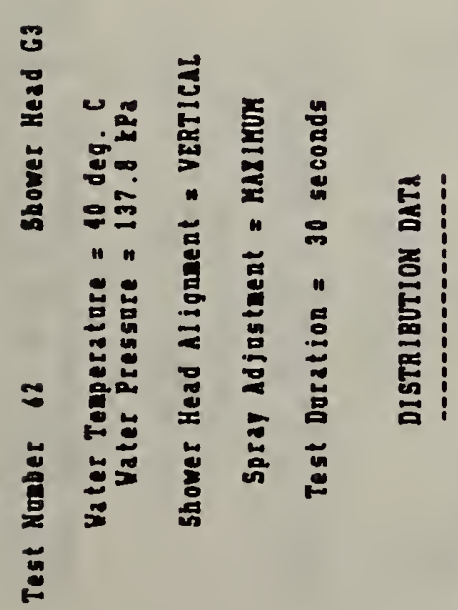

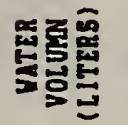

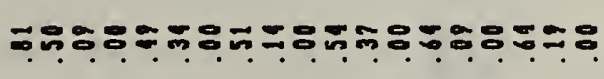

$\pm$

$\Xi$

$\because m:$

氮

ㄸㅐㅗ돓옴

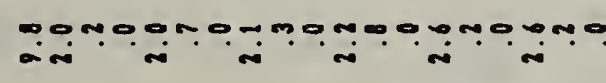

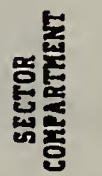

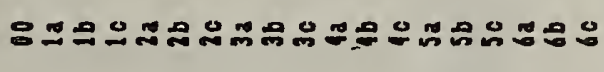

염

$\overrightarrow{2} \approx 0$

in:

11

10

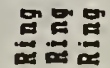

" " "

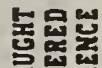

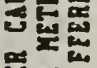

点禹告

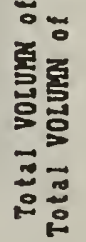



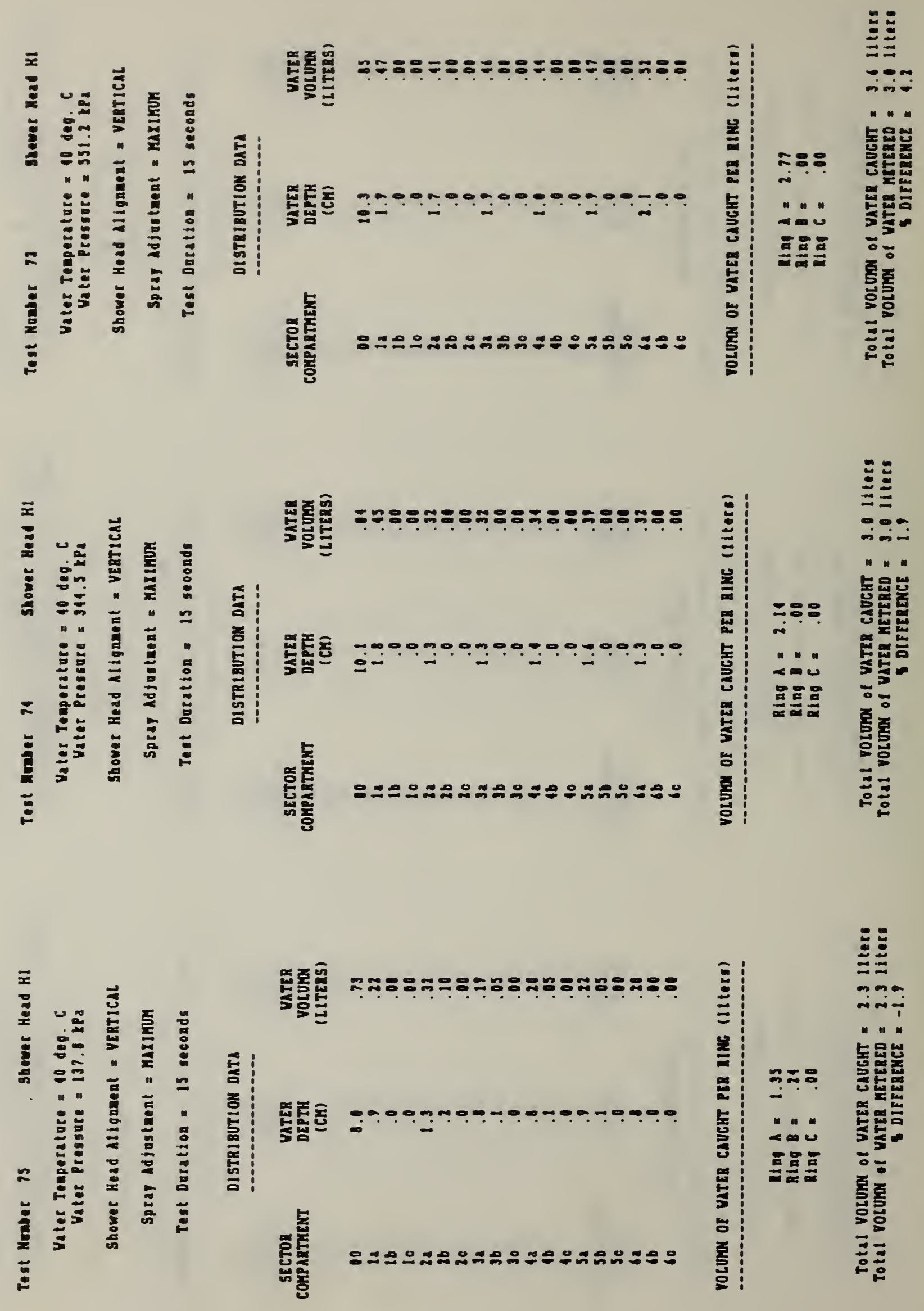

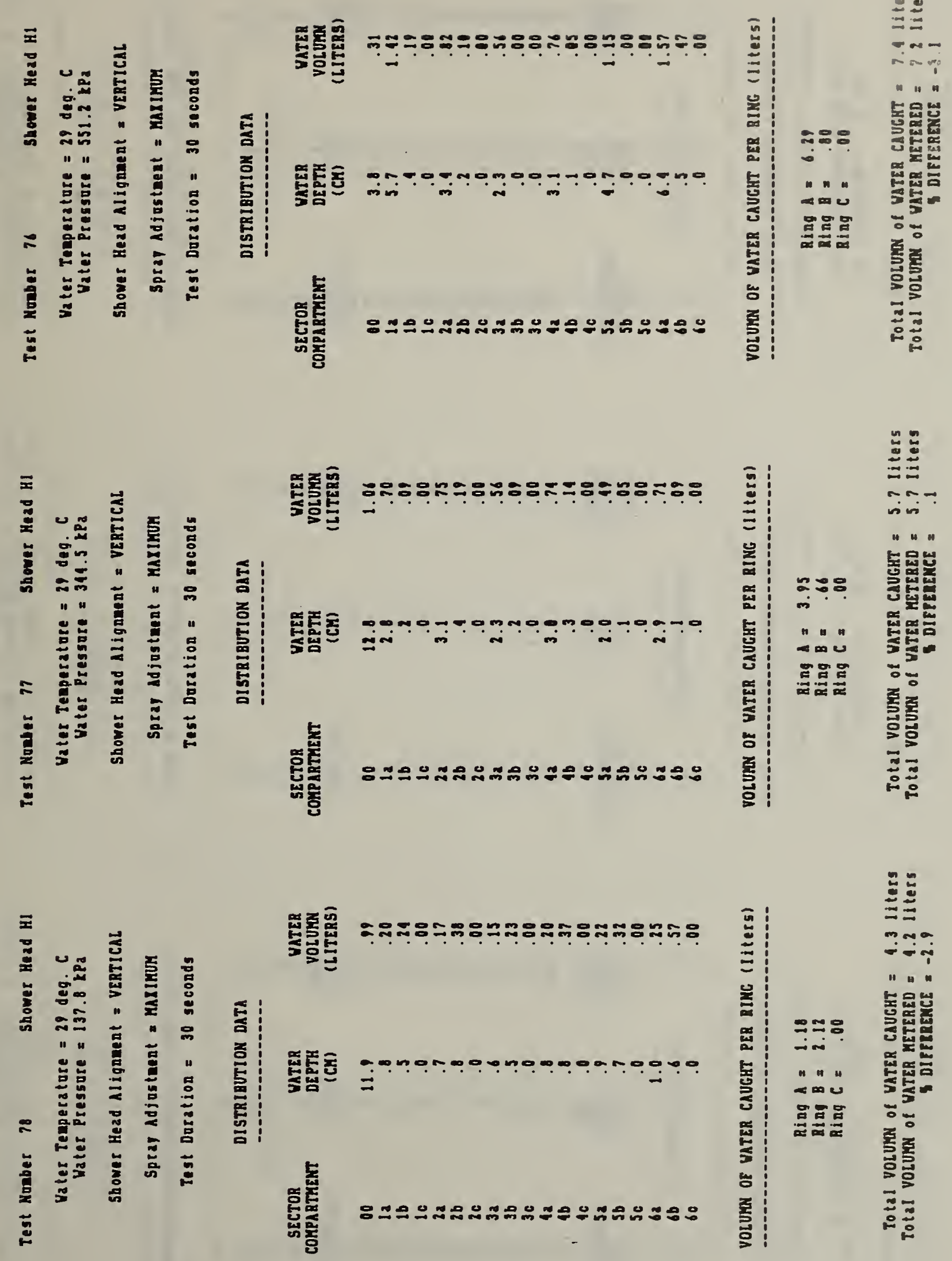

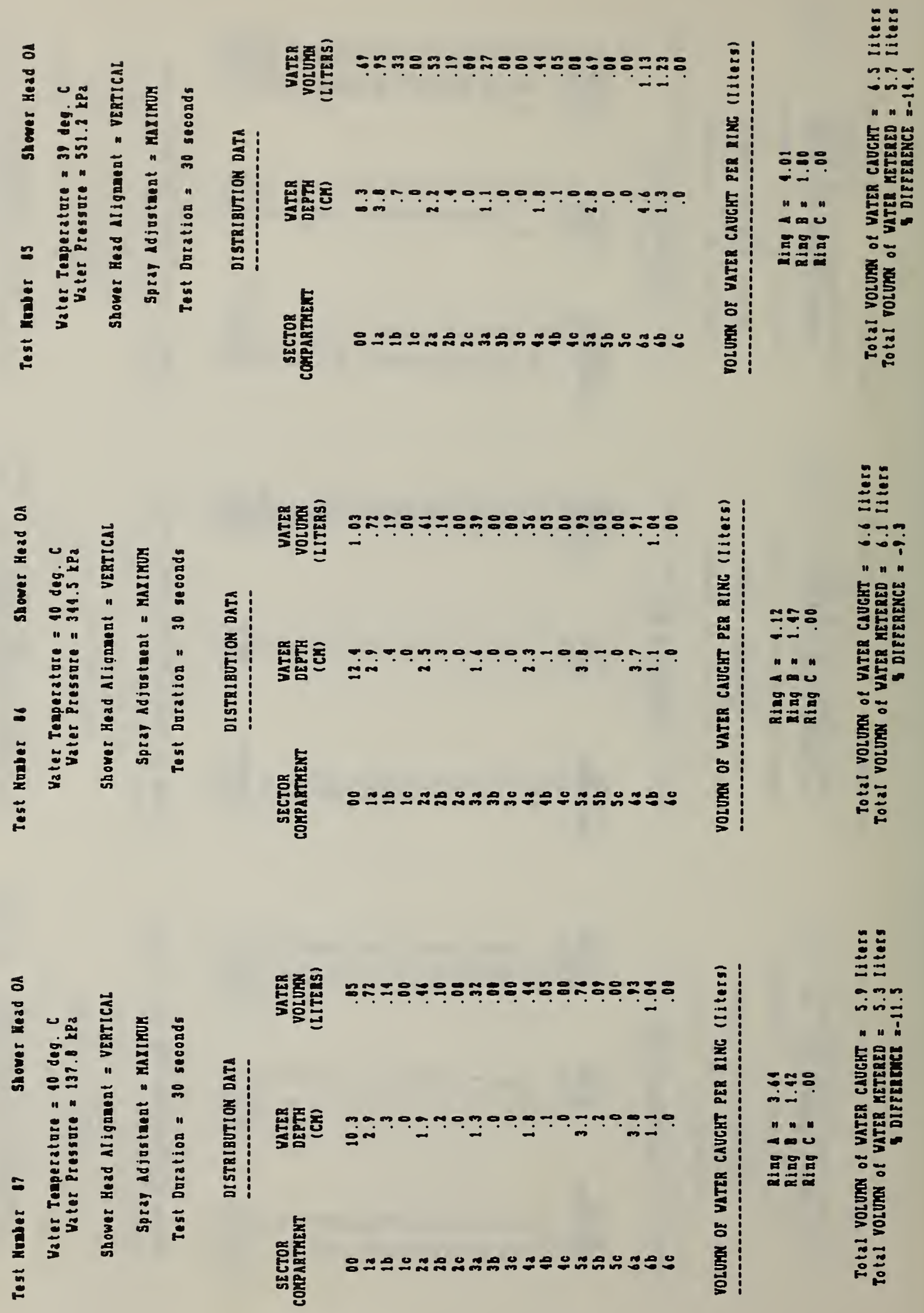

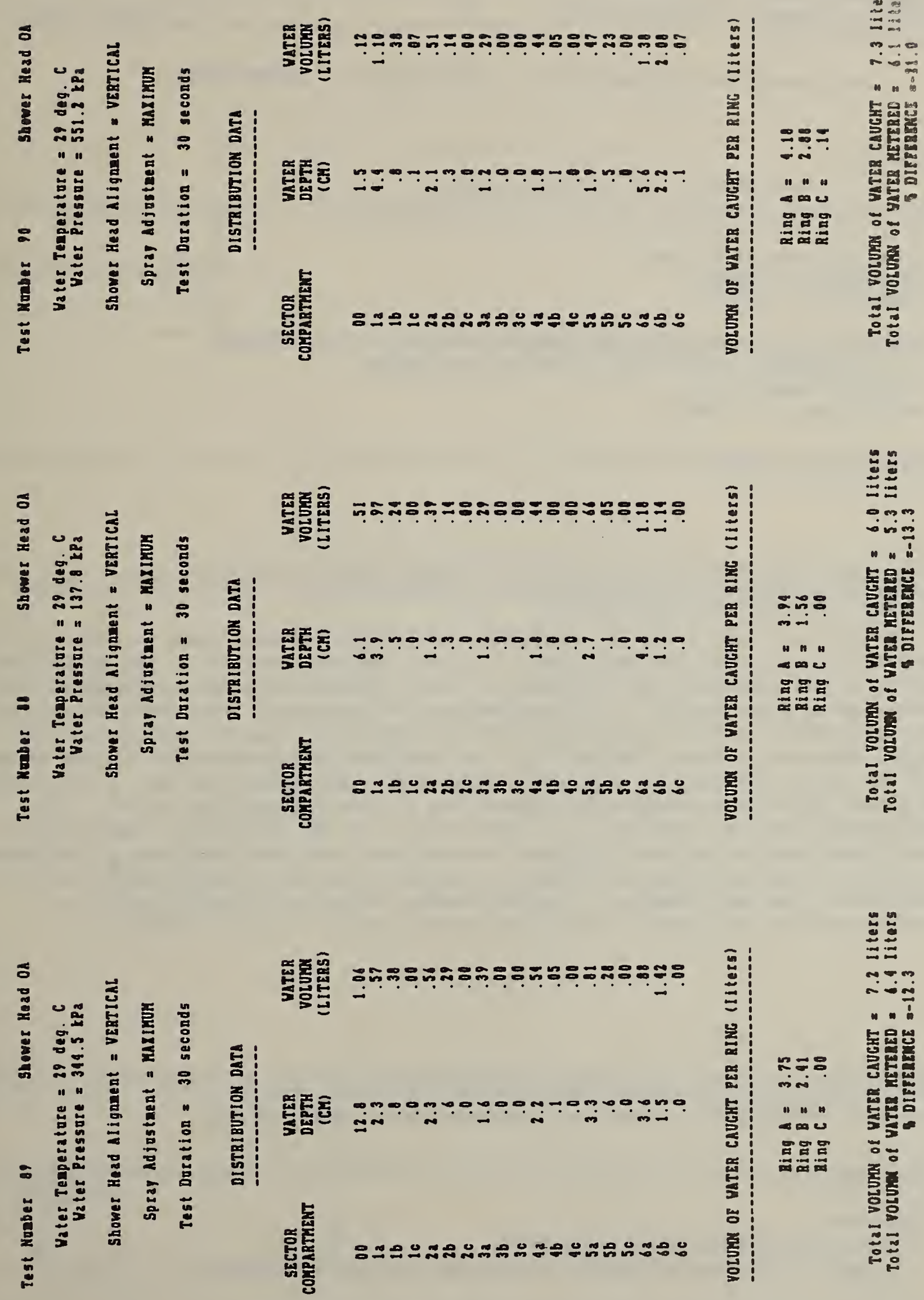
NBS-114A IREV. 2-6C)

\begin{tabular}{|c|c|c|}
\hline U.S. DEPT. OF COMM. & $\begin{array}{l}\text { 1. PUBLICATION OR } \\
\text { REPORT NO. }\end{array}$ & 2. Performing Organ. Report Nof 3. Publication Date \\
\hline SHEET (See in & NBSIR $82-2630$ & February 1983 \\
\hline
\end{tabular}

4. TITLE AND SUBTITLE

DEVELOPMENT AND EVALUATION OF A TEST METHOD FOR SHOWER HEADS

5. AUTHOR(S)

Paul Kopetka and Lawrence Galowin

6. PERFORMING ORGANIZATION (If joint or other than NBS, see in structions)

7. Contract/Grant No.

NATIONAL BUREAU OF STANDARDS

DEPARTMENT OF COMMERCE

8. Type of Report \& Period Covered

WASHINGTON, D.C. 20234

9. SPONSORING ORGANIZATION NAME AND COMPLETE ADDRESS (Street, City, State, ZIP)

U.S. Department of Housing and Urban Development

4517 th Street, SW

Washington, D.C. 20410

10. SUPPLEMENTARY NOTES

Document describes a computer program; SF-185, FIPS Software Summary, is attached.

11. ABSTRACT (A 200-word or less factual summary of most significant information. If document includes a significant bibliography or literature survey, mention it here)

A proposed test method for the evaluation of low-flow shower heads or flow-restrictormodified shower heads was developed. The test method provides for the measurement of the principal operating characteristics, 1.e., pressure-flow rate dependency and the shower spray distribution. The requirements for laboratory instrumentation suitable for application to the apparatus and the procedures for testing were established. A water collection device, "sector rig," was designed and constructed for the measurement of spray distribution patterns. Experiments were conducted with a small number of shower heads to determine the suitability of the proposed test method. The experimental results indicated the applicability of the method for measurement of spray distribution patterns and other conventional hydraulic performance parameters. A proposed test method for evaluation of shower heads was prepared based upon the analysis of the test results. The test method includes the specification of instrumentation, apparatus, procedures, measurements, and data reduction.

12. KEY WORDS (Six to twelve entries; alphabetical order: capitolize only proper names; and separate key words by semlcolons) plumbing; showerheads; water supply devices;water conservation

\section{AVAILABILITY}

XX] Unlimited

For Official Distribution. Do Not Release to NTIS

Order From Superintendent of Documents, U.S. Government Printing Office, Washington, D.C. 20402.

\#类 Order From National Technical Information Service (NTIS), Springfield, VA. 22161
14. NO. OF PRINTED PAGES

64

15. Price

$\$ 10.00$ 

